\title{
DETERMINAÇÃO DA COR DO SOLO E SUA UTILIZAÇÃO NA PREDIÇÃO DOS TEORES DE HEMATITA
}

\section{ROGÉRIO COSTA CAMPOS}

Dissertação apresentada à Escola Superior de Agricultura "Luiz de Queiroz", da Universidade de São Paulo, para obtenção do título de Mestre em Agronomia, Área de concentração: Solos e Nutrição de Plantas.

P I R A C I C A B A

Estado de São Paulo - Brasil

Novembro - 2001 


\section{DETERMINAÇÃO DA COR DO SOLO E SUA UTILIZAÇÃO NA PREDIÇÃO DOS TEORES DE HEMATITA}

\section{ROGÉRIO COSTA CAMPOS}

Engenheiro Agrônomo

Orientador: PROF. DR. JOSÉ ALEXANDRE M. DEMATTÊ

Dissertação apresentada à Escola Superior de Agricultura "Luiz de Queiroz", da Universidade de São Paulo, para obtenção do título de Mestre em Agronomia, Área de Concentração: Solos e Nutrição de Plantas.

PIRACICABA

Estado de São Paulo - Brasil

Novembro - 2001 


\section{Dados Internacionais de Catalogação na Publicação (CIP) DIVISÃO DE BIBLIOTECA E DOCUMENTAÇÃO - ESALQ/USP}

Campos, Rogério Costa

Determinação da cordo solo e sua utilização na predição dosteores de hematita / Rogério Costa Campos. -- Piracicaba, 2001.

$59 \mathrm{p}$.

Dissertação (mestrado) - Escola Superior de Agric ultura Luiz de Queiroz, 2001. Bibliografia.

1. Cor do solo 2. Classific ação do solo 3. Hematita 4. Minerologia do solo 5. Sensoria mento remoto I. Título

CDD 631.43

“Permitida a cópia total ou parcial deste documento, desde que citada a fonte - $\mathrm{O}$ autor" 
Aos meus pais Sônia e Rogaciano, a minha avó Teresa, ao meu tio Rosênio e ao irmão Thiago

pela confiança, amor e constante incentivo,

Ofereço

\author{
A Ana Julia e Daniela pela \\ fundamental inspiração na \\ realização do trabalho, \\ Dedico.
}




\section{AGRADECIMENTOS}

Ao Pai Celestial que permitiu-me cumprir mais uma etapa de minha vida.

Ao meu orientador e amigo, Professor José Alexandre M. Demattê, pela valorosa contribuição e dedicação, sem a qual, não poderia estar concluindo este trabalho.

Ao Curso de Pós-Graduação em Solos e Nutrição de Plantas da Escola Superior de Agricultura "Luiz de Queiroz", pela oportunidade.

À Fundação de Amparo e Pesquisa do Estado de São Paulo - FAPESP, pelo financiamento deste trabalho.

Aos amigos Aline, Fabiane, Nanni, Peterson, Marcio, Tiago, Carlos, Marcelo, Beatriz e Miguel pela amizade, apoio e companheirismo no desenvolvimento deste trabalho.

Ao Engenheiro Agrônomo Marcelo Alves do Centro de Informática na Agricultura (CIAGRI) da ESALQ/USP pelo auxílio na área de estatística.

Aos professores do curso de Pós-Graduação em Solos e Nutrição de Plantas da Escola Superior de Agricultura "Luiz de Queiroz", pêlos conhecimentos transmitidos.

Ao Instituto Nacional de Pesquisas Espaciais (Inpe - Departamento de Sensoriamento Remoto) pela utilização do sensor Fieldspec para a obtenção dos dados radiométricos das amostras de terra.

Ao Engenheiro Agrônomo Marcelo Eduardo Alves por ter cedido as amostras de terra e as análises de hematita. 
Aos funcionários do Departamento de Solos da Escola Superior de Agricultura "Luiz de Queiroz".

Aos professores Zilmar Ziller, Pablo Vidal, Hélio do Prado, Jairo Mazza, Marcos Nanni e José Luiz I. Demattê pela valorosa colaboração no desenvolvimento deste trabalho.

À todos aqueles, que de alguma maneira, contribuíram para a execução deste trabalho, agradeço. 


\section{SUMÁRIO}

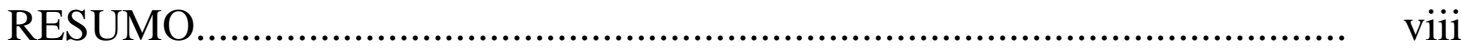

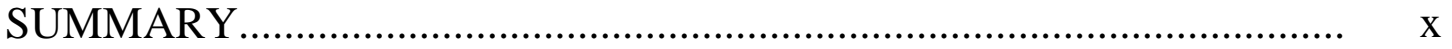

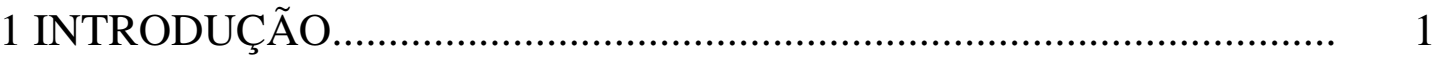

2 REVISÃO DE LITERATURA.............................................................

2.1 Importância da cor no estudo do solo e métodos para sua avaliação..... 4

2.2 Relação da cor com os constituintes do solo............................................ 7

3 MÉTODOS DE DETERMINAÇÃO DA COR DO SOLO: CARTA

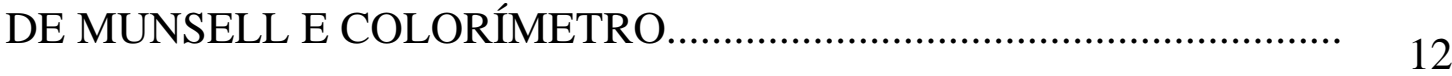

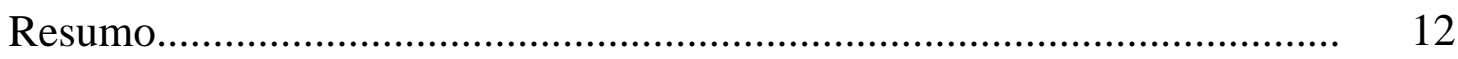

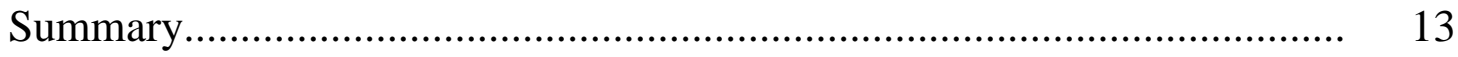

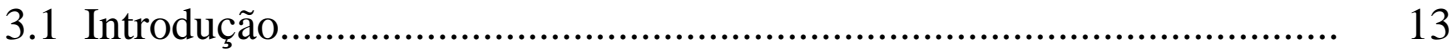

3.2 Material e Métodos........................................................................ 16

3.2.1 Áreas e solos de estudo....................................................................... 16

3.2.2 Avaliação da cor por pesquisadores................................................... 17

3.2.3 Medições da cor com colorímetro.......................................................... 17

3.2.4 Estabelecimento de limites para a cor obtida pelo colorímetro............ 19

3.2.5 Análise estatística para avaliação das determinações de cor

3.3 Resultados e Discussão..................................................................... 22

3.3.1 Análise de correlação entre as medidas de matiz obtidas por pesquisadores e através do colorímetro. 
3.3.2 Precisão dos pesquisadores na determinação da cor do solo

3.3.3 Determinações do matiz pelos pesquisadores e pelo colorímetro e sua influência na classificação dos solos.

3.3.4 Comportamento dos pesquisadores em relação aos limites rígidos e médios estabelecidos com os dados de colorímetro.....

3.4 Conclusões

4 QUANTIFICAÇÃO DO TEOR DE HEMATITA A PARTIR DA COR DO SOLO

Resumo 35

Summary. 36

4.1 Introdução. 36

4.2 Material e métodos. 40

4.2.1 Solos e análises mineralógicas.

4.2.2 Obtenção da curva de reflectância espectral 40

4.2.3 Determinação das cores. 40

4.2.4 Índices de avermelhamento. 43

4.3 Resultados e discussão. 43

4.4 Conclusões

5 CONCUSÕES GERAIS. 52

REFERÊNCIAS BIBLIOGRÁFICAS 


\title{
DETERMINAÇÃO DA COR DO SOLO E SUA UTILIZAÇÃO NA PREDIÇÃO DOS TEORES DE HEMATITA
}

\author{
Autor: ROGÉRIO COSTA CAMPOS \\ Orientador: Prof. Dr. JOSÉ ALEXANDRE M. DEMATTÊ
}

\section{RESUMO}

Os objetivos do presente trabalho foram: (a) Determinar e avaliar a cor dos solos pelo método convencional e com equipamento colorímetro e sua implicação na classificação de solos: (b) Estimar teores de hematita a partir da cor do solo. O matiz de 80 amostras de solos foi determinado por cinco experientes pesquisadores pela comparação com a carta de Munsell e diretamente com um colorímetro. A cor de 15 amostras de solos pertencentes a diferentes regiões do Estado de São Paulo foi determinada utilizando um colorímetro e a partir de dados de reflectância obtidos por radiômetro. As cores foram determinadas no sistema $L^{*} a^{*} b^{*}$ e Munsell. Para cada amostra foram determinados os teores de hematita e calculados os índices de avermelhamento (IAV) a partir das cores obtidas. Os coeficientes de correlação, variando de 0,68 a 0,94 entre as determinações do matiz, constataram que os pedólogos produziram dados que validaram o estudo. No entanto, houve confirmação de que as medidas realizadas por pedólogos não coincidem, sendo difeprentes também das determinações feitas pelo colorímetro. Índices de precisão (IP) indicaram haver concordância em 
apenas 8,75 \% das determinações em amostras úmidas e 17,5 \% nas amostras secas, sendo constatado que as divergências resultariam em erros na classificação dos solos. Os IAVs apresentaram alta correlação com os teores de hematita das amostras, sendo maior para correlações com índices determinados a partir de cores no sistema $\mathrm{L}^{*} \mathrm{a}^{*} \mathrm{~b}$ do que no sistema Munsell. Modelos exponenciais mostraram-se mais adequados na predição dos teores de hematita. 


\title{
SOIL COLOR DETERMINATION AND ITS USE ON THE ESTIMATIVE OF HEMATITE CONTENTS
}

\author{
Author: ROGÉRIO COSTA CAMPOS \\ Adviser: Prof. Dr. JOSÉ ALEXANDRE M. DEMATTÊ
}

\section{SUMMARY}

The objectives of the present work were: (a) Determine and evaluate color by the conventional method, and its comparison with colormeter equipment and their implication with soil classification; (b) Estimate of hematite contents by using soil color data. The hue of 80 samples of soils was determined by five experienced soil scientists by the comparison with the Munsell's soil color charts and by a colorimeter. Color of 15 soil samples from different sites of São Paulo State were determined by colorimeter and from reflectance data obtained with radiometer. The correlation coefficients, varying from 0,68 to 0,94 of hue determinations, showed that the soil scientists produced data that validated the study. However, there was confirmation that the measures accomplished by soil scientists were not coincident and also differed from the colormeter. The values of precision index (PI) indicated an agreement of only $8,75 \%$ in moist samples and $17,5 \%$ in the dry samples, which would result in mistakes in the soil classification. Colors were achieved by $\mathrm{L}^{*} \mathrm{a}^{*} \mathrm{~b} *$ and Munsell systems. For each 
sample, hematite content were determinated and the redness indexes (RI) calculated. The RI presented high correlation with hematite contents, and higher correlations for colors obtained in $\mathrm{L}^{*} \mathrm{a} \mathrm{b}^{*}$ than those obtained in Munsell system. Exponential models were more effective in predicting hematite contents. 


\section{INTRODUÇÃO}

A coloração apresentada pelos solos constitui uma das maneiras mais primitivas de identificá-los. Tratados antigos de agricultura escritos por filósofos gregos e romanos que viveram antes da Era Cristã, já classificavam os solos pela sua coloração. Como essa propriedade é função de características como o material de origem do solo e das condições climáticas predominantes, nessa época, procurou-se associar a cor do solo com a sua produtividade. Hoje, com o advento de metodologias para o estudo do solo sabe-se que outros atributos como matéria orgânica e a mineralogia são mais precisos que a cor na avaliação de sua fertilidade. No entanto, isso não torna menos importante o estudo da cor dos solos, haja visto que esta propriedade está intimamente relacionado aos constituintes do solo, principalmente à presença de óxidos de ferro e matéria orgânica, sendo portanto, a cor, um importante indicador da composição e da gênese do solo. Podemos ainda considerar, que a avaliação da cor ganha destacada importância, considerando que muitos sistemas de classificação de solos a utilizam como atributo separador das unidades de solo (FAO, 1989; Soil Survey Staff, 1988). No Sistema Brasileiro de Classificação de Solos (Embrapa, 1999), a cor determina o nome de ARGISSOLOS e LATOSSOLOS no segundo nível categórico e no primeiro nível de GLEISSOLOS e CHERNOSSOLOS.

Sabe-se que a coloração dos solos tem estreita relação com óxidos de ferro, principalmente hematita e goethita, o que tem justificado o empenho de inúmeros pesquisadores na tentativa de determinar a cor dos solos de forma mais exata e 
assim, estabelecer relações quantitativas entre a cor $\mathrm{e}$ os constituintes mineralógicos do solo.

Torna-se necessário atentar para as metodologias empregadas na determinação da cor. A precisão da medida da cor de um objeto é claramente afetada quando ocorre alguma modificação em algum dos três fatores dos quais ela é dependente: i) a natureza da fonte de luz que ilumina o objeto, ii) a característica da superfície do objeto, e iii) a sensibilidade espectral do receptor (Wyszecki \& Stiles, 1982).

Convencionalmente, a cor do solo é determinada pela comparação com a notação encontrada na caderneta de Munsell. Este é um método mundialmente utilizado por pedólogos devido a sua rápida e fácil aplicação em trabalhos de campo. No entanto, nem a fonte de luz e nem a subjetividade atribuída à interpretação de cada pesquisador são apropriadamente controlados na aquisição das medidas de cor obtidas por esse método. Por isso, é necessário desenvolver melhores metodologias para obtenção da cor do solo. Vários métodos têm sido propostos em trabalhos relacionados à cor do solo, sendo comum surgirem dificuldades em tentativas de utilizar os sistemas de ordem de cores para classificar todo o intervalo de cores em que os solos ocorrem.

Rotineiramente a cor do solo é determinada pela comparação visual com os padrões encontrados na carta de Munsell, raramente apresentando uma perfeita concordância com esses padrões (Soil Survey Staff, 1988). A cor pode ser medida utilizando-se os dados espectrais do solo, medidos por espectrofotômetros, radiômetros ou colorímetros (Escadafal et al., 1989). Esta técnica toma a energia refletida na região do visível e converte dentro do sistema de coordenadas da Commission Internationale de I’Eclairage (CIE, 1931). Portanto, medidas de cor podem ser realizadas utilizando instrumentos que são mais exatos que o subjetivo método utilizado pelos pedólogos. Assim, torna-se interessante que medidas de cor de solo, obtidas por pesquisadores, sejam comparadas entre si e entre medidas 
tomadas por aparelhos para que seja possível avaliar relações existentes e as possíveis implicações da utilização dos métodos nos sistemas de classificação de solos, bem como, a partir de uma metodologia mais precisa e exata para determinação da cor dos solos, estabelecer relação entre os constituintes do solo e a sua coloração, como por exemplo a hematita.

Desta forma, os objetivos deste trabalho foram: i) avaliar a cor do solo feita por pesquisadores comparando-as com determinações obtidas por um colorímetro, ii) avaliar a influência na classificação dos solos atribuída a metodologia utilizada para a determinação da cor e iii) avaliar a relação existente entre a cor dos solos determinada por sensores (colorímetro e radiômetro) com os teores de hematita. 


\section{REVISÃO DE LITERATURA}

\subsection{Importância da cor no estudo do solo e métodos para sua avaliação}

A cor é uma das mais importantes propriedades do solo. É devido à sua notável aparência que constitui, provavelmente, o principal atributo evidente deste (Santana, 1984; Soil Survey Staff, 1988). A cor do solo é determinada, principalmente, por pigmentos, como os óxidos de ferro e a matéria orgânica, e outros, como o conteúdo de umidade e a distribuição do tamanho de partículas (Fernandez \& Schulze, 1992). No campo, sua determinação é normalmente efetuada pela comparação visual de cores, utilizando a carta de Munsell. Torrent \& Barrón (1993) destacam que, devido a diversos fatores, erros substanciais estão envolvidos neste método de determinação visual e subjetivo, o que revela a importância do desenvolvimento de instrumentos de campo e laboratório que permitam uma determinação mais objetiva, precisa e exata.

A importância da cor do solo está no fato de algumas de suas características, como teores de hematita e goethita (Schwertmann \& Taylor, 1977) estarem a si relacionadas. Características do solo, como matéria orgânica e óxidos de ferro, têm forte relação com a cor, considerando ainda que são de grande importância na classificação dos solos. No entanto, alguns trabalhos relatam ocorrer determinada subjetividade na avaliação desse atributo, quando a sua avaliação ocorre convencionalmente, ou seja, pela comparação com a carta de Munsell. A precisão das medidas de cor no campo é limitada pelo intervalo 
existente entre os valores listados na carta de Munsell (Soil Survey Staff, 1988). Pomerening \& Knox (1962) relatam que o limite da precisão para medidas de cor em laboratório, foi de uma unidade para o matiz e de meia unidade para o valor e o croma.

Evans (1948) discute muitos aspectos a respeito da cor, relatando inúmeras dificuldades na realização de seu estudo, considerando-a subjetiva e muito complexa.

Melville \& Atkinson (1985) listam três fatores de maior efeito na subjetividade na interpretação da cor pelo olho humano: característica da fonte de luz que ilumina o objeto a ter a cor medida, características da superfície do objeto e qualidade da resposta espectral do olho humano.

A interpretação da cor pelo olho humano não se dá de forma quantitativa, ficando a interpretação restrita à termos pouco específicos como amarelo, vermelho, verde, entre outros. Os resultados dessa avaliação influem na classificação de solos (Camargo et al., 1987; Embrapa, 1999). Portanto tal influência sugere o estabelecimento de metodologias que quantifiquem a cor do solo, evitando erros na classificação dos mesmos.

Melville \& Atkinson (1985) discutiram detalhadamente medições de cor utilizando uma série de modelos. Fernandez \& Shulze (1987) avaliaram a cor do solo pelo espectro de reflectância e constataram haver ganho em exatidão e precisão, tornando possível quantificar sutis diferenças de cor nos solos, o que é de reconhecida dificuldade quando são utilizados apenas os recursos do olho humano. Devido a isso, técnicas quantitativas envolvendo a cor vêm sendo avaliadas.

Post et al. (1993) relatam a realização de medições da cor do solo utilizando colorímetro (Minolta Corp., Ramsey, NJ), com o qual foi possível fazer medidas precisas. Em seguida, esses pesquisadores compararam as medidas do colorímetro com medidas feitas com os recursos do olho humano. Estes 
autores também avaliaram a precisão da cor medida utilizando o método tradicional da carta de cores de Munsell para avaliação de campo. Além disso, avaliaram como vários cientistas interpretaram a cor da mesma amostra de solos utilizando o sistema de cor de Munsell, concluindo que houve concordância em $52 \%$ na interpretação da cor e $71 \%$ quando foi analisado um único componente da cor. Concluíram ainda, que o colorímetro tem excelente potencial para realizar medições quantitativas de cor, podendo ser utilizado com sucesso na sua avaliação.

Kelly \& Judd (1976) relatam que um observador experiente consegue expressar sua máxima capacidade em distinguir cores, apenas em condições de laboratório, com iluminação controlada, utilizando amostras devidamente preparadas e uma carta de Munsell completa.

A subjetividade na avaliação da cor do solo determinada pelo olho humano, tem influência direta na classificação dos solos. O segundo nível categórico de classificação (Embrapa, 1999), de algumas classes de solo é dado pela notação de cor determinada pela comparação com a carta de Munsell. Por exemplo, a cor de ARGISSOLOS e LATOSSOLOS define a nomenclatura do segundo nível categórico desses dois grandes grupos de solos.

De acordo com a lei da colorimetria, um objeto com uma dada reflectância espectral, produz, sob uma dada condição de iluminação, uma e apenas uma sensação de cor para um observador normal (Billmeyer \& Saltzman, 1981). No entanto, Sánchez - Marañon et al. (1995), comparando a avaliação da cor de solos efetuada por pessoas treinadas com a utilização das cadernetas de Munsell, com o uso de aparelhos espectrofotométricos, concluíram que há grande divergência entre as duas formas de avaliação. As divergências são atribuídas à sensibilidade do observador à distância entre duas páginas consecutivas da referida carta, o que obriga interpolações nem sempre adequadas. A estimativa da cor com o uso de equipamentos foi considerada a de maior precisão e reprodutibilidade. 
Demattê \& Garcia (1999), utilizando espectroradiômetro em laboratório obtiveram elevados valores de $\mathrm{R}^{2}$ para o valor e o matiz, quando correlacionados com os dados de reflectância.

\subsection{Relação da cor com os constituintes do solo}

Costa (1979) já afirmava que muitas das propriedades do solo podem ser estimadas com base na reflectância espectral e que se deveria investir na busca da utilização mais rotineira de um instrumento de laboratório que medisse esta propriedade para amostras de solo.

O sistema solo pode ser considerado uma mistura de partículas minerais e orgânicas que interagem com a luz incidente, não sendo completamente transparentes e nem completamente opacas; portanto, as partículas parcialmente absorvem e parcialmente dispersam a luz incidente (Barrón \& Torrent, 1986). Torrent \& Barrón (1993) basearam-se nesse princípio para proporem a determinação em laboratório da cor de amostras de solos pela Espectroscopia de Reflectância Difusa, utilizando os mesmos aparelhos espectrofotométricos comuns em laboratórios, com pequenas adaptações. A luz que incide sobre uma amostra de solo, refletida de maneira difusa, é adquirida e analisada, promovendo um espectro, ou curva de reflectância, dentro do intervalo de comprimento de onda considerado, normalmente de 400 a $700 \mathrm{~nm}$.

Além dos trabalhos desenvolvidos por Torrent e colaboradores, outros autores também utilizaram técnicas espectrofotométricas com aplicação em estudos da cor em edafologia: Nagano \& Nakashima (1989), com solos do Japão; Fernandéz \& Schulze (1992), com misturas de óxidos de ferro sintéticos e caulinita; e Madeira Netto et al. (1997), com solos brasileiros.

As informações dos espectros obtidos são convertidas diretamente em valores triestímulos $\mathrm{X}, \mathrm{Y}$ e $\mathrm{Z}$ (correspondentes ao conteúdo de vermelho, verde e 
azul, respectivamente) e suas respectivas coordenadas $\mathrm{x}, \mathrm{y}$ e $\mathrm{z}$, conforme proposto pelo sistema CIE (1931). Essas coordenadas tricromáticas podem ser transformadas informaticamente, ou por tabelas de correlação, em outros sistemas mais perceptíveis ao olho humano, como o CIE-L*a*b* ( $\mathrm{L}^{*}$ de luminosidade, $a *$ de um eixo que varia de vermelho a verde e $b^{*}$ de um eixo que varia de amarelo a azul) e o sistema Munsell, com base nos atributos matiz, croma e valor.

Procedimentos informáticos baseados nos valores das diferentes estimativas anteriores permitem ainda a obtenção dos chamados índices vermelhos (RR, FV, etc.) de forma mais precisa e menos subjetiva.

O sistema CIE-L*a*b* é uma ferramenta utilizada por mais de $90 \%$ dos usuários de diversas áreas da ciência (Sánchez-Marañon et al., 1995), embora tenha pouca expressão nos trabalhos com solos. Já o sistema Munsell é o mais conhecido entre os pedólogos, estando presente nas cadernetas de campo de avaliação da cor do solo.

O método de determinação das propriedades da cor do solo proposto por Barrón \& Torrent (1986) utiliza amostras secas, podendo ser efetuado com pequenas quantidades de material e de maneira relativamente simples. Os valores obtidos por esta técnica são considerados mais precisos, uma vez que se evitam interpolações imprecisas, falta de reprodutibilidade e erros subjetivos, passíveis de ocorrer na determinação visual.

Informações práticas para a utilização da técnica de reflectância difusa no que se refere a metodologia de preparo das amostras, dados acerca do portaamostra utilizado, preparação e seleção de brancos (padrões), instrumentais a serem acoplados ao espectrofotômetro convencional, condições de leitura e fatores que interferem na determinação são apresentados por Torrent \& Barrón (1993) e Barrón et al. (1999). A adaptação necessária a um espectrofotômetro convencional de laboratório consiste basicamente da incorporação de uma esfera de reflectância, que permite coletar o fluxo de luz refletido da amostra analisada, 
conduzindo as informações coletadas, em cada comprimento de onda, diretamente ao aparelho, para posterior tratamento dos dados.

Uma das principais aplicações desta técnica é a possibilidade de considerações de natureza quantitativa da amostra analisada, principalmente a partir da utilização da teoria de Kubelka-Munk (1931), como apresentada por Barrón (1985) e Barrón \& Torrent (1986). Esta teoria trata de meios túrbidos, nos quais poderia ser incluído o solo, por possuir partículas que podem, simultaneamente, absorver e dispersar a luz incidente. A partir desta teoria, obtém-se uma equação que expressa a relação entre a reflectância difusa apresentada pela amostra e determinados coeficientes que a caracterizam, em especial os coeficientes de absorção e de dispersão. Estes coeficientes cumprem uma lei aditiva, ou seja, o coeficiente de uma mistura de pigmentos é a combinação linear do somatório dos coeficientes individuais de seus componentes, de acordo com sua concentração. Essa propriedade permite a estimativa dos conteúdos dos diferentes pigmentos presentes em uma amostra de solo, sendo necessária somente uma prévia caracterização destes, no intuito de determinar seus coeficientes individuais médios. Posteriormente, e por meio de técnicas de dissolução seletiva, é possível a obtenção de um conjunto de equações que, resolvidas, permitem a avaliação quantitativa da amostra (Barrón et al., 1999).

Rezende (1980) já apontava a técnica espectrofotométrica como promissora para estimar a relação hematita:goethita em amostras de solo, uma vez que observou comportamento diferenciado dos espectros obtidos em função da referida relação para solos brasileiros. Um padrão característico, em torno de 440 a $460 \mathrm{~nm}$, foi identificado e relacionado com o aumento de goethita na amostra, embora o autor tenha encontrado dificuldades em mensurá-lo.

Dentre as possibilidades da aplicação quantitativa dos dados obtidos de cor, destaca-se a utilização da segunda derivada da curva de reflectância (Kosmas 
et al., 1984; Scheinost et al., 1998), que permite, de maneira mais simples, a estimativa de minerais dos solos. A curva da segunda derivada apresenta bandas com mínimos e máximos em determinados intervalos de comprimento de onda, que são associados aos minerais dos solos, em especial a goethita e hematita, facilitando assim sua identificação e mensuração. A sensibilidade desse procedimento matemático foi comprovada por Scheinost et al. (1998), os quais observaram que a adição de $0,05 \%$ de qualquer um destes dois óxidos de ferro a um material de solo desferrificado promoveu modificação significativa nas curvas obtidas, possível de ser medida.

Apesar de a cor dos pigmentos já ser conhecida, ocorrem fatores que podem afetar sua expressão e variações são observadas, com implicações diretas na cor do solo. Torrent \& Schwertmann (1987) observaram, para misturas de hematitas sintéticas e caulinitas, que a cor dependia do tamanho da partícula do óxido de ferro e que o aumento deste tamanho resultava em cores mais púrpuras, o que denota diminuição da capacidade de pigmentação da hematita. Essa relação, entretanto, não foi observada em amostras naturais de sedimentos vermelhos (red beds).

A substituição por alumínio nos óxidos de ferro também pode influenciar a cor dos minerais, como destacado por Norrish \& Taylor (1961) ao observarem picos de goethita no DRX de uma amostra de coloração creme-pálida, obtida após o tratamento do DCB. A cor observada para o resíduo sugeriria uma completa remoção dos óxidos de ferro do solo; entretanto, a observação dos difratogramas sugeriu que essas goethitas seriam de mais difícil remoção, coincidindo com as que apresentavam os maiores valores de substituição por alumínio. Este fenômeno foi considerado pelos autores como um fator de promoção da diminuição da coloração do óxido.

Já a matéria orgânica interfere no efeito dos minerais de ferro sobre a cor e reflectância de amostras de solo, principalmente para aquelas com conteúdos de 
matéria orgânica superiores a $17 \mathrm{~g} \mathrm{~kg}^{-1}$ e de $\mathrm{Fe}_{2} \mathrm{O}_{3}$ inferiores a $100 \mathrm{~g} \mathrm{~kg}^{-1}$ (Galvão \& Vitorello, 1998). No entanto, Fernandes et al. (1998) não observaram efeito da matéria orgânica nos padrões de reflectância de LATOSSOLOS brasileiros.

Em geral, poucos estudos têm sido realizados para avaliar a variação entre pedólogos na determinação da cor do solo (Post et al., 1993). Tampouco sobre como esse atributo se relaciona com os constituintes do mesmo. Uma melhor compreensão da relação entre a cor e os atributos do solo deve ser buscada, sendo necessário para isso, investir no desenvolvimento de métodos mais eficientes para a determinação da cor do solo. 


\section{MÉTODOS DE DETERMINAÇÃO DA COR DO SOLO: CARTA DE MUNSELL E COLORÍMETRO}

\section{RESUMO}

A determinação da cor é útil na diferenciação e caracterização dos solos. Portanto, o objetivo deste trabalho foi o de avaliar a cor do solo obtida pelos métodos convencional e por um colorímetro e as possíveis implicações na classificação de solos. Para isso, cinco pedólogos foram convidados a classificar o matiz de 80 amostras de terra através da comparação com a carta de Munsell. Em seguida, o matiz das amostras foi obtido com um colorímetro, também na notação de Munsell. Pelas análises estatísticas foram avaliados coeficientes de correlação, índice de precisão (IP), forma de agrupamento e tendências médias entre as determinações de matiz. Coeficientes de correlação variando de 0,68 a 0,94 entre as determinações de cor constataram que os pedólogos produziram dados que validaram o estudo. No entanto, houve confirmação de que as medidas realizadas por pedólogos não coincidem, sendo diferentes também das determinações feitas pelo colorímetro. Índices de Precisão (IP) indicaram haver concordância em apenas 8,75 \% das determinações em amostras úmidas e 17,5 \% nas amostras secas. Ocorreram divergências na determinação do matiz das amostras que resultaria em erros na classificação dos solos. A avaliação das tendências médias indicaram que os pesquisadores superestimaram as determinações de cor realizada pelo colorímetro, resultando em alterações na classificação de solos. 


\section{Summary: METHODS OF SOIL COLOR DETERMINATION BY MUNSELL' S CHART AND COLORMETER}

Determination of color is an useful tool in the differentiation and characterization of the soils. The objective of this work was to evaluate the conventional method of soil color determination, its relationship with the colorimeter method and the possible implications in soil classification. Five soil scientists were invited to determine the hue of 80 earth samples through the comparison with Munsell color. The hue of the samples was also obtained with a colorimeter. Through statistical analyses, were determined correlation coefficients, a the precision index (PI), that groups the average and tendencies of hue determinations. Correlation coefficients varying from 0,68 to 0,94 showed that soil scientists

produced precise data, fundamental for the validity of the study. However, it can be established that measures accomplished by soil scientists were not coincident, and were quite different from colormeter were not precise. The values of Precision Index (IP) indicated an agreement of only 8,75\% in moist samples and $17,5 \%$ in the dry samples. Divergences in hue determination implicates in mistakes on soil classification. The evaluation of average tendencies indicated that the researches superestimated color values in relation to colorimeter, resulting in alterations in soil classification.

\subsection{INTRODUÇÃO}

A cor é um dos mais úteis atributos para caracterizar e diferenciar solos, sendo sua determinação de grande importância no estudo de solos. Rotineiramente, a cor é determinada no campo pela sua comparação visual da com padrões existentes em cartas de cor (Munsell Soil Color Company, 1975). No entanto, devido a fatores físicos e psicofísicos, muitos erros estão envolvidos 
no método visual de determinação da cor, atribuindo-lhe características subjetivas. Várias peculiaridades sobre a cor dos solos, no que diz respeito aos fatores que a determinam e influenciam sua obtenção, são apresentadas em trabalhos realizados por Bigham \& Ciolkosz, (1993).

A cor do solo é função, principalmente, da presença de óxidos de ferro e matéria orgânica e outros, como o conteúdo de umidade e a distribuição do tamanho de partículas (Fernandez \& Schulze, 1992). Torrent \& Barrón (1993) comentam que, devido a diversos fatores, erros substanciais estão envolvidos neste método de determinação visual e subjetivo, uma vez que não são controlados fatores tais como a luz incidente sobre o objeto bem como a padronização das interpretações feitas pelo observador, o que acaba por evidenciar a importância do desenvolvimento de instrumentos de campo e laboratório que permitam determinação mais objetiva, precisa e exata.

Comparando a avaliação da cor de solos efetuada por pessoas treinadas com a utilização da carta de Munsell e com o uso de aparelhos espectrofotométricos, Sanchez-Marañon et al. (1995) concluíram que grande distância entre duas páginas consecutivas da referida carta, obriga interpolações nem sempre adequadas. A estimativa da cor com o uso de equipamentos foi considerada a de maior precisão.

Costa (1979) já afirmava que muitas das propriedades do solo podem ser estimadas com base na reflectância espectral e que se deveria investir na busca da utilização mais rotineira de um instrumento de laboratório que medisse esta propriedade para amostras de solo.

O sistema solo pode ser considerado uma mistura de partículas minerais e orgânicas que interagem com a luz incidente, não sendo completamente transparentes e nem completamente opacas; portanto, as partículas parcialmente absorvem e parcialmente dispersam a luz incidente (Barrón \& Torrent, 1986). Torrent \& Barrón (1993) basearam-se nesse princípio para proporem a 
determinação em laboratório da cor de amostras de solos pela Espectroscopia de Reflectância Difusa, utilizando os mesmos aparelhos espectrofotométricos comuns em laboratórios, com pequenas adaptações. A luz que incide sobre uma amostra de solo, refletida de maneira difusa, é adquirida e analisada, promovendo um espectro, ou curva de reflectância, dentro do intervalo de comprimento de onda considerado, normalmente de 400 a $700 \mathrm{~nm}$.

Além dos trabalhos desenvolvidos por Torrent e colaboradores, outros autores também utilizaram técnicas espectrofotométricas com aplicação em estudos da cor em edafologia: Nagano \& Nakashima (1989), com solos do Japão; Fernandéz \& Schulze (1992), com misturas de óxidos de ferro sintéticos e caulinita; e Madeira Netto et al. (1997), com solos brasileiros.

A subjetividade na avaliação da cor do solo determinada pelo olho humano, tem influência direta na classificação dos solos. O segundo nível categórico de classificação, segundo Embrapa (1999), de algumas classes de solo é dado pela notação de cor determinada pela comparação com a carta de Munsell. Por exemplo, a cor de ARGISSOLOS e LATOSSOLOS define a nomenclatura do segundo nível categórico desses dois grandes grupos de solos.

Determinações de cor fazendo uso de instrumentos capazes de interpretar a cor de um objeto a partir de sua interação com uma fonte de luz, produzem determinações mais exatas que a cor determinada pelo olho humano (Post et al., 1993). Dada a importância da cor, é necessário buscar determinações mais precisas para que esse parâmetro possa ser empregado adequadamente no estudo do solo.

A cor do solo determinada pelo olho humano, em função de características como capacidade de interpretação da cor e habilidade, particulares a cada observador, deve apresentar divergências quando diferentes pesquisadores determinam a cor de uma mesma amostra de solo. A comparação das determinações de cor feitas pelo olho humano com determinações feitas com um 
colorímetro, pode indicar tendências individuais de cada indivíduo em determinar a cor, sendo que as medidas feitas com o colorímetro não apresentam a subjetividade, das medições realizadas com o olho humano.

Os objetivos deste trabalho foram: (i) avaliar o comportamento de pesquisadores na determinação da cor do solo, (ii) avaliar as implicações na classificação de solos ocorridas em função de divergências na determinação da cor do solo e (iii) comparar a determinações da cor do solo feitas por pesquisadores e por um colorímetro.

\subsection{MATERIAL E MÉTODOS}

\subsection{1 Áreas e solos de estudo}

Foram utilizadas amostras de terra coletadas em duas áreas denominadas

como Áreas 1 e 2, obtendo maior heterogeneidade de solos. A Área 1 se encontra na região de Rafard, SP possuindo clima, segundo Köppen, Cwa caracterizado por inverno seco com verão chuvoso. De acordo com Embrapa (1979), grande parte da área está compreendida na classe de relevo ondulado. A geologia da área é composta por folhelhos, arenitos e diabásios.

As amostras utilizadas no estudo pertencem aos LATOSSOLO VERMELHO, LATOSSOLO VERMELHO AMARELO, ARGISSOLO VERMELHO AMARELO, ARGISSOLO VERMELHO, REGOSSOLO, NEOSSOLO, E NITOSSOLO classificados por Nanni (2000), de acordo com (Embrapa, 1999).

A Área 2 localiza-se na região de Barra Bonita, SP. O clima dessa área segundo a classificação de Köppen também é do tipo Cwa. A geologia da área é composta principalmente pelo diabásio. 
As amostras de terra coletadas nessa área pertencem às unidades LATOSSOLO VERMELHO e NITOSSOLO VERMELHO (Embrapa, 1999).

Foram escolhidas 65 amostras de terra localizadas na área de Rafard, SP e 15 amostras na região de Barra Bonita, SP. A escolha foi realizada tendo como finalidade a obtenção da maior variabilidade possível na cor das amostras.

\subsubsection{Avaliação da cor por pesquisadores}

Foram convidados cinco pesquisadores, sendo a escolha baseada no histórico da visão geral de cada um, em comum todos são pedólogos, porém desenvolvem trabalhos abordando a pedologia sob diferentes enfoques. Entre eles encontram-se classificadores de solos, estudiosos específicos em gênese, estudiosos da relação existente entre classificação e manejo de solos e, inclusive, participantes da elaboração da nova Classificação Brasileira (Embrapa, 1999).

Sub-amostras foram catalogadas e alocadas em uma bancada no interior de uma sala com fonte de iluminação artificial. Com isso, pretendeu-se padronizar a fonte de luz, garantindo a mesma condição de iluminação para todos os pesquisadores na ocasião da determinação da cor. Em seguida os pesquisadores receberam instruções para determinar o componente matiz da cor para as amostras secas e úmidas pela comparação com os padrões encontrados na carta de Munsell.

\subsubsection{Medições da cor com colorímetro}

A cor das amostras foi medida com um colorímetro Minolta, modelo CR300 que interpreta a cor a partir da energia refletida na região do visível. A energia refletida é oriunda da interação da amostra com espectro de luz, que para as determinações foi estabelecido o iluminante $\mathrm{C}$ que simula a luz natural. $\mathrm{O}$ 
equipamento determina a cor no sistema de coordenada XYZ e em seguida, o mesmo obtém a cor na notação Munsell, comparada para fins de discussão com as medidas realizadas pelos pesquisadores. Para simular a percepção visual da cor por um "olho humano" padronizado, o colorímetro possui um sensor que quantifica a energia refletida da interação da luz com o objeto, sendo utilizados os triestímulos imaginários básicos propostos pela CIE (1931). A CIE (1931) definiu o observador padrão para as medidas de cor segundo os valores de triestímulos denotados $\bar{x}(\lambda), \bar{y}(\lambda)$ e $\bar{z}(\lambda)$ (Figura 1).

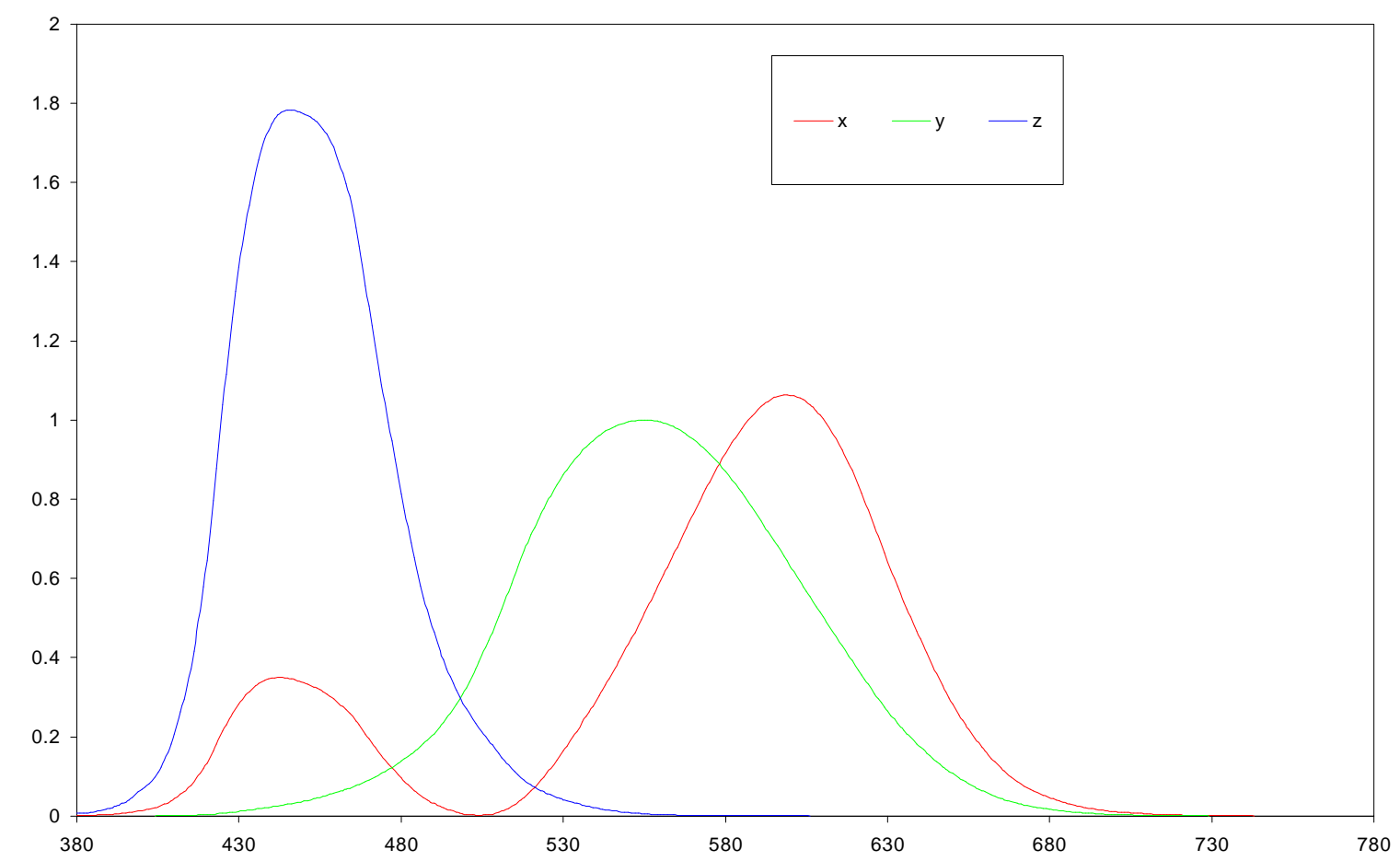

Comprimento de onda, $\mathrm{nm}$

Figura 1- Sensibilidade espectral para o olho humano segundo um observador padrão (CIE, 1931). 


\subsubsection{Estabelecimento de limites para a cor obtida pelo colorímetro}

As medidas de cor feitas pelo colorímetro podem ser obtidas em intervalos intermediários que não são apresentados na carta de Munsell, conferindo maior precisão e exatidão a essas determinações. No entanto, para que pudesse ser realizada a análise estatística visando a comparação entre os matizes obtidos pelos pesquisadores e pelo colorímetro, as determinações obtidas com o colorímetro foram transformadas, adotando limites rígidos e médios, em valores apresentados na carta de Munsel. Assim, dependendo do intervalo de matiz determinado com o colorímetro a transformação foi realizada (Tabela 1).

Tabela 1. Intervalos estabelecidos para transformar os valores da cor medidos com o colorímetro adotando limites rígidos e limites médios.

\begin{tabular}{ccc}
\hline Intervalo de Matizes & $\begin{array}{c}\text { Valor transformado } \\
\text { adotando limites médios }\end{array}$ & $\begin{array}{c}\text { Valor transformado } \\
\text { adotando limites rígidos }\end{array}$ \\
\hline$>8.75 \mathrm{R}$ e $\leq 10 \mathrm{R}$ & $10 \mathrm{R}$ & $10 \mathrm{R}$ \\
$>10 \mathrm{R} \mathrm{e} \leq 1.25 \mathrm{YR}$ & $10 \mathrm{R}$ & $2.5 \mathrm{YR}$ \\
$>1.25 \mathrm{e} \leq 2.5 \mathrm{YR}$ & $2.5 \mathrm{YR}$ & $2.5 \mathrm{YR}$ \\
$>2.5 \mathrm{YR} \mathrm{e} \leq 3.75 \mathrm{YR}$ & $2.5 \mathrm{YR}$ & $5 \mathrm{YR}$ \\
$>3.75 \mathrm{e} \leq 5 \mathrm{YR}$ & $5 \mathrm{YR}$ & $5 \mathrm{YR}$ \\
$>5 \mathrm{YR} \mathrm{e} \leq 6.25 \mathrm{YR}$ & $5 \mathrm{YR}$ & $7.5 \mathrm{YR}$ \\
$>6.25 \mathrm{YR}$ e $\leq 7.5 \mathrm{YR}$ & $7.5 \mathrm{YR}$ & $7.5 \mathrm{YR}$ \\
$>7.5 \mathrm{YR} \mathrm{e} \leq 8.75 \mathrm{YR}$ & $7.5 \mathrm{YR}$ & $10 \mathrm{YR}$ \\
$>8.75 \mathrm{YR} \mathrm{e} \leq 10 \mathrm{YR}$ & $10 \mathrm{YR}$ & $10 \mathrm{YR}$ \\
$>10 \mathrm{YR} \mathrm{e} \leq 1.25 \mathrm{Y}$ & $10 \mathrm{YR}$ & $2.5 \mathrm{Y}$ \\
$>1.25 \mathrm{Y}$ e $\leq 2.5 \mathrm{Y}$ & $2.5 \mathrm{Y}$ & $2.5 \mathrm{Y}$ \\
\hline
\end{tabular}




\subsubsection{Análise estatística para avaliação das determinações de cor}

Os limites rígidos e médios foram estabelecidos com a intenção de verificar as implicações da avaliação da cor na Classificação Brasileira de Solos (Embrapa, 1999) uma vez que este sistema estabelece limites de variação de cor para diferenciar alguns solos. Especificamente, os limites médios foram criados para analisar qual a tendência do pesquisador, quando a cor da amostra se apresenta em intervalos não contemplados na carta de Munsell. Assim, foi possível determinar qual o comportamento do pesquisador quando ele determina valores de matiz contidos em intervalos da carta de Munsell. Quando os valores coincidem com limites médios, entende-se que o pesquisador atribui ao matiz da amostra o valor mais próximo contido na carta Munsell. Já a coincidência com valores rígidos indica uma tendência do pesquisador em superestimar os valores de matiz.

Por se tratar de dados qualitativos, a obtenção de cor feita pelos pesquisadores foi transformada em dados ordinais para que a análise pudesse ser realizada. Assim, com base na variação de cor do conjunto de amostras, os matizes foram transformados tendo em vista a variação do vermelho para o amarelo, estabelecendo-se a seguinte ordem: $10 \mathrm{R}=1,2.5 \mathrm{YR}=2,5.0 \mathrm{YR}=3$, $7.5 \mathrm{YR}=4,10 \mathrm{YR}=5$ e $2.5 \mathrm{Y}=6$.

A análise estatística foi realizada utilizando o programa Statistical Analisys System, SAS (1989). Relações entre as determinações de matiz realizadas no trabalho, foram estabelecidas pela análise de coeficientes de correlação de Spearman.

Com a finalidade de avaliar como as determinações do matiz se agrupavam, bem como sua correlação com o grupo estatístico que integra, foi realizada a análise de "Cluster". 
Através da análise de dados pareados foram verificadas as tendências médias entre as determinações do matiz, possibilitando avaliar qual o comportamento de uma avaliação em relação a outra.

Visando estabelecer a precisão da avaliação da cor pelos pesquisadores e pelo colorímetro, foi criado o índice de precisão (IP), calculado através da soma do valor da diferença, em valor absoluto, entre todas as combinações das determinações de matiz para mesma amostra, de modo que para a uma determinada amostra temos:

$$
\begin{aligned}
& (\mathrm{P} 1-\mathrm{P} 2)+(\mathrm{P} 1-\mathrm{P} 3)+(\mathrm{P} 1-\mathrm{P} 4)+(\mathrm{P} 1-\mathrm{P} 5)+(\mathrm{P} 1-\mathrm{C})=\mathrm{n} 1 \\
& (\mathrm{P} 2-\mathrm{P} 3)+(\mathrm{P} 2-\mathrm{P} 4)+(\mathrm{P} 2-\mathrm{P} 5)+(\mathrm{P} 2-\mathrm{C})=\mathrm{n} 2 \\
& (\mathrm{P} 3-\mathrm{P} 4)+(\mathrm{P} 3-\mathrm{P} 5)+(\mathrm{P} 3-\mathrm{C})=\mathrm{n} 3 \\
& (\mathrm{P} 4-\mathrm{P} 5)+(\mathrm{P} 4-\mathrm{C})=\mathrm{n} 4 \\
& (\mathrm{P} 5-\mathrm{C})=\mathrm{n} 5 \\
& \text { sendo; } \\
& \mathrm{P}_{(1,2,3,4 \text { e 5) }} \text { é a leitura feita pelos pesquisadores } \\
& \text { C é a leitura feita pelo colorímetro }
\end{aligned}
$$

Assim, IP é igual a $(n 1+n 2+n 3+n 4+n 5)$. Portanto, quanto maior a divergência entre as determinações de cor para uma mesma amostra, maior será o valor de IP, sendo o contrário também verdadeiro.

Será considerado, para fins de discussão, que as determinações de cor pelos cinco pesquisadores, serão denominadas P1, P2 , P3 , P4 e P5, bem como as leituras de cor feitas pelo colorímetro serão denominadas C_M quando referente à transformação baseada em limites médios e C_R quando adotados limites rígidos para conversão. 


\subsection{RESULTADOS E DISCUSSÃO}

\subsubsection{Análise de correlação entre as medidas de matiz obtidas por pesquisadores e através do colorímetro}

A ordenação do matiz, como descrita na metodologia, possibilitou a realização de uma série de análises que permitiram avaliar tendências, discordâncias e concordâncias que ocorreram entre as determinações do matiz das amostras de terra determinadas por pesquisadores e pelo colorímetro. Desta forma, foi possível realizar algumas considerações a respeito do método convencional e o colorímetro na determinação da cor do solo, bem como as consequiências na classificação dos mesmos.

Os valores do coeficiente de correlação de Spearman (Tabela 2), sugerem que em geral, as correlações entre as medidas de cor são altas, tanto para as leituras feitas nas amostras secas como úmidas. A variação no coeficiente de correlação foi de 0,68 a 0,93 indicando haver coerência entre as medições de cor realizadas. Provavelmente a coerência pôde ser atribuída ao treinamento e a habilidade dos pesquisadores, bem como a precisão do equipamento, confirmando as constatações de Post et al. (1993). As correlações entre as avaliações indicou que o potencial do aparelho em realizar as medições e a habilidade dos pesquisadores, não permitiu a ocorrência de divergências substanciais, o que significa dizer que não houve discordância entre pontos distantes na variação do matiz de uma mesma amostra em Munsell.

Quase que de forma geral, as correlações indicaram que as medidas de cor feitas por P1 e P2 foram as de menor concordância com as determinações da cor das amostras feitas pelo colorímetro e pelos demais pesquisadores. Assim, fica evidente que P1 e P2 compõem um caso isolado entre as demais avaliações. Este 
Tabela 2. Resultado dos coeficientes de correlação de Spearman entre as determinações do Matiz das amostras secas e úmidas

\begin{tabular}{|c|c|c|c|c|c|c|c|}
\hline \multicolumn{8}{|c|}{ Coeficiente de correlação entre determinação da cor de amostras secas } \\
\hline & P1 & $\mathrm{P} 2$ & P3 & P4 & P5 & C_R & C_M \\
\hline P1 & 1,00 & 0,78 & 0,76 & 0,77 & 0,75 & 0,75 & 0,73 \\
\hline P2 & 0,78 & 1,00 & 0,77 & 0,80 & 0,72 & 0,77 & 0,73 \\
\hline P3 & 0,76 & 0,77 & 1,00 & 0,89 & 0,93 & 0,91 & 0,90 \\
\hline P4 & 0,77 & 0,80 & 0,89 & 1,00 & 0,93 & 0,90 & 0,87 \\
\hline P5 & 0,75 & 0,72 & 0,93 & 0,93 & 1,00 & 0,93 & 0,92 \\
\hline C_R & 0,75 & 0,77 & 0,91 & 0,90 & 0,93 & 1,00 & 0,89 \\
\hline C_- M & 0,73 & 0,73 & 0,90 & 0,87 & 0,92 & 0,89 & 1,00 \\
\hline \multicolumn{8}{|c|}{ Coeficiente de correlação entre determinação da cor de amostras úmidas } \\
\hline & P1 & P2 & P3 & P4 & P5 & C_R $R$ & C_M \\
\hline P1 & 1,00 & 0,72 & 0,72 & 0,71 & 0,69 & $0, \overline{6} 9$ & 0,69 \\
\hline P2 & 0,72 & 1,00 & 0,82 & 0,85 & 0,82 & 0,82 & 0,81 \\
\hline P3 & 0,72 & 0,82 & 1,00 & 0,90 & 0,94 & 0,91 & 0,93 \\
\hline P4 & 0,71 & 0,85 & 0,90 & 1,00 & 0,91 & 0,90 & 0,92 \\
\hline P5 & 0,69 & 0,82 & 0,94 & 0,91 & 1,00 & 0,91 & 0,94 \\
\hline C_R & 0,69 & 0,82 & 0,91 & 0,90 & 0,91 & 1,00 & 0,89 \\
\hline C_M & 0,69 & 0,81 & 0,93 & 0,92 & 0,94 & 0,89 & 1,00 \\
\hline
\end{tabular}

fato pode ser observado para a determinação da cor seca. No entanto, para a cor úmida, embora se mantenha a correlação entre os pesquisadores, também é notado o aumento da correlação de P2 com os demais pesquisadores e o colorímetro.

Outro ponto a ser destacado, é a elevada correlação entre P3, P5 e as medidas de cor feitas pelo colorímetro (Tabela 2). Em geral, esses pesquisadores apresentaram-se como capazes de realizar medições mais ajustadas às medições realizadas pelo colorímetro.

A análise de "Cluster" permitiu agrupar os resultados, obtidos por pesquisadores e pelo colorímetro, em grupos cuja característica foi a proximidade entre as leituras da cor das amostras de solo. Quatro grupos foram 
formados com os dados referentes a determinação do matiz das amostras secas e úmidas (Tabela 3). A análise de Cluster para o matiz da amostra agrupou P3, P4, P5 e C_R, determinando a formação do grupo 1, os grupos isolados 2 , 3, e 4 foram formados, respectivamente, por P1, P2 e C_M. A forma como os grupos se compuseram, confirma a análise de correlação (Tabela 2), uma vez que é indicada clara diferença de P1 e P2 em relação às demais avaliações, o que confirma as constatações de Torrent \& Barrón (1993) no que se refere aos erros envolvidos no método convencional de determinação da cor do solo. Tal fato, é confirmado tanto para as amostras secas como úmidas. A separação dos grupos gerados para a leitura da cor úmida, continua a evidenciar divergências de P1 e P2 em relação à demais medidas, sendo que estes também formaram grupos isolados mediante a análise destes dados.

Tabela 3. Grupos formados pela análise de "Cluster" para as determinações do matiz das amostras secas e úmidas e os coeficientes de correlação das determinações com os respectivos grupos.

\begin{tabular}{|c|c|c|c|}
\hline \multicolumn{2}{|c|}{ Cor da amostra seca } & \multicolumn{2}{|c|}{ Cor da amostra úmida } \\
\hline $\begin{array}{l}\text { Componentes } \\
\text { do "Cluster" }\end{array}$ & $\begin{array}{l}\mathrm{R}^{2} \text { com o } \\
\text { respectivo } \\
\text { "Cluster" }\end{array}$ & $\begin{array}{l}\text { Componentes do } \\
\text { "Cluster" }\end{array}$ & $\begin{array}{l}\mathrm{R}^{2} \text { com o respectivo } \\
\text { "Cluster" }\end{array}$ \\
\hline \multicolumn{4}{|c|}{ “Cluster” 1} \\
\hline P3 & 0,92 & P3 & 0,94 \\
\hline P4 & 0,91 & P5 & 0,93 \\
\hline P5 & 0,95 & C_R & 0,91 \\
\hline C_R & 0,92 & C_M & 0,92 \\
\hline \multicolumn{4}{|c|}{ "Cluster" 2} \\
\hline $\mathrm{P} 2$ & 1,00 & $\mathrm{P} 1$ & 1,00 \\
\hline \multicolumn{4}{|c|}{ "Cluster" 3} \\
\hline P1 & 1,00 & $\mathrm{P} 2$ & 1,00 \\
\hline \multicolumn{4}{|c|}{ “Cluster" 4} \\
\hline C_M & 1,00 & $\mathrm{P} 4$ & 1,00 \\
\hline
\end{tabular}


Os valores de correlação entre os grupos formados, bem como a composição dos grupos, também confirmam a maior aproximação de P3 e P5 e as determinações realizadas pelo colorímetro.

Observando os valores de correlação entre os "Clusters" (Tabela 3), podese considerar que as divergências não ocorrem substancialmente, confirmando que os pesquisadores são experientes e treinados para realizar a determinação do matiz através da notação de Munsell. No entanto, embora treinados e dotados de habilidade, pode-se averiguar a ocorrência de diferentes posições tomadas pelos pesquisadores em relação à determinação da cor de uma mesma amostra de terra. $\mathrm{Na}$ ocasião deste trabalho, muito provavelmente, as determinações de cor estão melhor correlacionados do que aconteceria na prática. Somando-se à habilidade dos pesquisadores, a obtenção das cores das amostras aconteceu em condições controladas laboratório, que segundo Kelly \& Judd (1976), é onde um observador experiente consegue expressar a sua máxima capacidade em distinguir cores, eliminando as diferenças atribuídas aos fatores de influência, que não são controladas em condições de campo. Portanto, as divergências na determinação da cor entre os pesquisadores pode ser atribuída à algumas características individuais.

Chamberlin \& Chamberlin (1980) discutem como o cone do nervo central do olho humano, que percebe a cor em três áreas de sensibilidade diferente, sendo essas áreas sensíveis ao azul, ao verde e ao vermelho, implica na percepção de cor por algumas pessoas. Esta teoria tricromática, explica que algumas pessoas são menos eficientes em discriminar cor. Esses autores afirmam que $8 \%$ da população mundial tem dificuldade em discriminar cores, o que pode explicar parte da variabilidade dos dados. Fatores como qualidade da luz incidente e qualidade da carta de cores utilizada não podem estar associados às divergências ocorridas entre os pesquisadores, uma vez que para essas determinações esses 
fatores foram os mesmos. Post et al. (1993), relatam que tiveram grande dificuldade em isolar todas as variáveis que estariam causando uma possível influência na determinação da cor pelos pesquisadores. Isso se deu em função do grande número de pesquisadores envolvidos no estudo, por isso não puderam ser consideradas as condições de iluminação em que as cores foram determinadas, uma vez que as amostras foram enviadas aos pesquisadores, bem como a real habilidade de cada pesquisador em determinar a cor do solo. Embora tenha sido enviado um questionário direcionado a obtenção de informações a respeito de em quais condições o experimento foi conduzido, os autores julgaram que não houve consistência nas informações obtidas. Neste trabalho, a iniciativa de controlar as condições para a determinação da cor das amostras, foi portanto, de fundamental importância.

\subsubsection{Precisão dos pesquisadores na determinação da cor do solo}

Muitos trabalhos relacionados à determinação da cor do solo, enfocam a rara concordância entre as determinações realizadas pela comparação com os padrões encontrados na carta de Munsell, porém são poucos os que avaliam de forma quantitativa as imprecisões deste método. Em nenhum trabalho consultado foi possível encontrar resultados direcionados à determinação da intensidade das diferenças, o que possibilitaria atribuir significados e implicações associados à distribuição e intensidade das divergências, bem como possíveis implicações das divergências em estudos relacionados a determinação da cor do solo.

Para avaliar o quanto as medições de cor variaram dentro de uma mesma amostra, foi estabelecido o IP (Índice de Precisão). Pelo IP, foi possível avaliar a intensidade das divergências que ocorreram na determinação das cores das amostras de terra, bem como ela se distribui. Considerando que o valor de IP representa o valor da soma do módulo da diferença entre todas as determinações 
dentro da mesma amostra, pode-se, portanto, considerar que quanto maior o valor de IP atribuído à amostra, maior foi a divergência entre as leituras para esta amostra. Por outro lado, quanto menor o IP, maior a concordância entre as determinações.

Nota-se que para a cor úmida, o valor médio de IP foi de 10,9 (Tabela 4), significando que em média houve duas determinações, na mesma amostra, diferentes em um ponto das demais determinações. Vale ressaltar, que em função da ordenação dos dados para realização da análise estatística, a diferença de 1 ponto nos dados ordenados, significa uma variação de 2.5 pontos em Munsell. Portanto, chama-se a atenção para que em um trabalho de classificação de solos, seguindo a rigor o Sistema Brasileiro de Classificação de Solos (Embrapa, 1999) poderia ocorrer divergência na classificação do solo.

Em sete das amostras cujo matiz foi determinado com a amostra úmida, o valor de IP foi igual a zero, indicando não haver diferença entre as determinações da cor destas amostras. Neste caso, não houve divergência na determinação da cor do solo. Ocorrem também, dentro desta distribuição, valores que indicam grande discordância entre determinações de cor. Valor de IP igual a 28, 22 e 20 ocorrem uma, duas e três vezes respectivamente, embora sejam ocorrências isoladas, esses valores indicam haver imprecisão na determinação da cor destas amostras, sugerindo elevado grau de discordância entre as determinações.

Para as cores das amostras secas, foram observadas as mesmas tendências observadas na análise de IP realizada para as amostras úmidas (Tabela 4). O valor médio de IP foi de 9,55 o que significa dizer que a grandeza e a intensidade das divergências são bastante próximas entre as determinações da cor das amostras secas e úmidas. 
Tabela 4. Valores de IP distribuídos segundo o número de ocorrências, de acordo com as determinações de cor.

\begin{tabular}{cccc}
\hline \multicolumn{2}{c}{ Determinação em amostras secas } & \multicolumn{2}{c}{ Determinação em amostras úmidas } \\
\hline $\begin{array}{c}\text { Número de } \\
\text { ocorrências }\end{array}$ & Valor de IP $^{1}$ & $\begin{array}{c}\text { Número de } \\
\text { ocorrências }\end{array}$ & Valor de IP $^{1}$ \\
14 & 0 & 7 & 0 \\
18 & 6 & 18 & 6 \\
14 & 10 & 15 & 10 \\
18 & 12 & 18 & 12 \\
3 & 16 & 12 & 16 \\
7 & 18 & 4 & 18 \\
3 & 20 & 2 & 20 \\
3 & 22 & 3 & 28 \\
0 & 28 & 1 & 28 \\
0 & 28 & 1 & Média =10,96 \\
$\Sigma=80^{2}$ & Média $^{3}=9,55$ & $\sum=80$ & \\
\hline
\end{tabular}

${ }^{1}$ IP: Índice de precisão; ${ }^{2}$ Total de amostras análisadas; ${ }^{3}$ Média ponderada em função do número de ocorrências.

A baixa ocorrência de valores altos de IP, sugerindo baixa ocorrência de erros substanciais, também foi observada na avaliação da cor seca. A diferença notada, foi a maior ocorrência de amostras com valor de IP igual a zero, sendo 14 amostras para a cor seca contra sete amostras para a cor úmida.

\subsubsection{Determinações do matiz pelos pesquisadores e pelo colorímetro e sua influência na classificação dos solos}

Para Billmeyer \& Saltzman (1981), um objeto com uma dada reflectância espectral e sob uma condição de iluminação, deve produzir a mesma sensação de cor para um observador normal. Devido à diferença de iluminação, determinada divergência seria entre a determinação feita por pesquisadores e pelo colorímetro, já que a fonte luz foi a mesma para os pesquisadores, porém diferente para o colorímetro. No entanto, tal diferença deveria ser constante, assumindo caráter 
semelhante para todas as determinações feitas por pesquisadores quando comparadas com o colorímetro. Como pôde ser observado (Tabelas 2, 3 e 4) diferentes posições foram tomadas pelos pesquisadores em relação ao colorímetro concordando com Sánchez-Marañon et al., (1995). Sendo assim, outros fatores influenciaram os resultados de determinação de cor.

$\mathrm{Na}$ análise de variação entre as médias das leituras de cor (Tabela 5) é possível observar como uma determinação se comporta, em média, em relação a outra. São apresentadas todas as combinações onde são mostradas as tendências médias de uma determinação em relação a outra.

O Sistema Brasileiro de Classificação de Solos (Embrapa, 1999), classifica o segundo nível categórico de alguns solos, por exemplo ARGISSOLOS e LATOSSOLOS, de acordo com intervalos de variação de matiz estabelecidos na carta de Munsell. Em média, a determinação de matiz P1, para amostras secas, foi 0,5 menor que para P2 (Tabela 5) na escala de valores ordenados. Através do valor de $\mathrm{P}=000.1$, é confirmado que essa tendência não é ao acaso, mas sim, uma característica de P1 em relação a P2, bem como todas as tendências médias avaliadas. Em Munsell, a diferença em 0,5 na escala ordenada, significa dizer que há uma diferença de 1,25 pontos, o que poderia implicar em divergências na determinação da cor de amostras de solos.

Em quase todas as comparações, P1 apresentou tendência em subestimar o valor da cor das amostras em relação às outras determinações. Tal característica é uma tendência desse pesquisador, já que o mesmo pode ser observado para a determinação do matiz da amostra úmida.

Tomando a rigor os limites de variação de matiz para a classificação de solos no sistema brasileiro, possíveis erros podem ocorrer em função das divergências médias constatadas. Um mesmo solo, por exemplo um LATOSSOLO, é classificado como VERMELHO, quando possui matiz igual ou mais vermelho 2.5YR e VermelHo AMARElo, quando o matiz for mais vermelho que 5YR e 
mais amarelo que 2.5YR. Em função dos limites estabelecidos para classificação dos solos e das divergências na determinação da cor constatadas nesse trabalho, pesquisadores poderiam classificar diferentemente um mesmo solo.

Tabela 5. Tendências médias existentes entre as determinações do valor de matiz para amostras secas e úmidas.

\begin{tabular}{cccc}
\hline $\begin{array}{c}\text { Comparação entre as } \\
\text { determinações }\end{array}$ & M1 & M2 $2^{(1)}$ & Valor de $^{(3)}$ \\
\hline P1 x P2 & $-0,48148$ & $-0,5000$ & 0,0001 \\
P1 x P3 & $-0,06173$ & $-0,0750$ & 0,0001 \\
P1 x P4 & $-0,45679$ & $-0,4375$ & 0,0001 \\
P1 x P5 & 0,11111 & $-0,1500$ & 0,0001 \\
P1 x C_R & $-0,25926$ & $-0,3375$ & 0,0001 \\
P1 x C_M & 0,28395 & 0,0500 & 0,0001 \\
P2 x P3 & 0,41975 & 0,4250 & 0,0001 \\
P2 x P4 & 0,02469 & 0,0625 & 0,0001 \\
P2 x P5 & 0,59259 & 0,3500 & 0,0001 \\
P2 x C_R & 0,22222 & 0,1625 & 0,0001 \\
P2 x C_M & 0,76543 & 0,5500 & 0,0001 \\
P3 x P4 & $-0,39506$ & $-0,3625$ & 0,0001 \\
P3 x P5 & 0,17284 & $-0,0750$ & 0,0001 \\
P3 x C_R & $-0,19753$ & $-0,2625$ & 0,0001 \\
P3 x C_M & 0,34568 & 0,1250 & 0,0001 \\
P4 x P5 & 0,56790 & 0,2875 & 0,0001 \\
P4 x C_R & 0,19753 & 0,1000 & 0,0001 \\
P4 x C_M & 0,74074 & 0,4875 & 0,0001 \\
P5 x C_R & $-0,37037$ & $-0,1875$ & 0,0001 \\
P5 x C_M & 0,17284 & 0,2000 & 0,0001 \\
C_R x C_M & 0,54321 & 0,3875 & 0,0001
\end{tabular}

() Tendência média para determinação do matiz em amostras úmidas. ${ }^{(2)}$ Tendência média para determinação do matiz em amostras secas. ${ }^{(3)}$ Valor de $\mathrm{P}=0,0001$ confirmando Ho: $\mu$ diferente de 0. Obs: valores negativos subestimam e valores positivos superestimam as determinações de matiz na escala ordenada.

Pela análise das comparações entre as tendências médias, pode-se dizer que as diferenças não são ao acaso, mas sim devido a existência de tendências entre as determinações de cor, particulares a cada pesquisador. Tais tendências, segundo Soil Survey Staff (1988) podem estar relacionadas ao comportamento 
do pesquisador quando estes determinam a cor de amostras que possuem matizes contidos em valores intermediários aos apresentados na carta de Munsell. Nesse caso, o avaliador tem que escolher se vai atribuir à amostra, o valor inferior ou superior de matiz.. Portanto, o comportamento dos pesquisadores (Tabela 5), pode estar relacionado a tomada de decisão a respeito da cor de uma amostra sem a existência de um padrão definido para comparação devido aos intervalos contidos na carta de Munsell.

\subsubsection{Comportamento dos pesquisadores em relação aos limites rígidos e médios estabelecidos com os dados de colorímetro}

Post et al. (1993), encontraram baixo valor de desvio padrão, bem como baixo coeficiente de variação na obtenção da cor determinada com colorímetro de um conjunto de solos possuidores de uma ampla variação de cor. Encontraram também, modelos de regressão linear com altos valores de coeficientes de correlação $\left(r^{2}=0.99\right)$ entre cores determinadas pelo colorímetro e vários padrões de cor encontrados na carta de Munsell. Assim, esses autores puderam comprovar que esse equipamento é exato e preciso na determinação da cor do solo. Concluindo nesse mesmo trabalho, que o mesmo não é valido para determinações feitas por pesquisadores utilizando a carta de Munsell.

Com base nas constatações no que diz respeito ao potencial do equipamento em realizar medidas mais exatas e precisas, foram realizadas comparações entre medidas feitas por pesquisadores e pelo colorímetro. Em uma tentativa de avaliar o comportamento de cada pesquisador de forma mais precisa, foram estabelecidos limites rígidos e médios para conversão dos dados de cor obtidos com o colorímetro em padrões contidos na carta de Munsell. Assim, foi possível averiguar qual a real tendência dos pesquisadores em determinar a cor do 
solo nos intervalos não padronizados da carta de Munsell e sua importância na classificação dos solos.

Quanto ao comportamento dos pesquisadores em relação aos limites estabelecidos, pode-se observar que houve diferença. Em geral, nas análises das tendências médias (Tabela 5), os pesquisadores tendem a superestimar os valores médios. Segundo Cooper (1990), em função do número limitado de padrões da carta de Munsell, existe uma tendência, não fundamentada, dos pesquisadores realizarem a notação atribuindo valores mais altos para a cor.

Os limites estabelecidos a partir de valores rígidos proporcionam uma avaliação diante de uma eventual tendência de os pesquisadores superestimarem os valores contidos em intervalos da carta de Munsell. Diante disso, pode-se dizer que, quanto menores as diferenças médias, da comparação da determinação da cor feita pelo pesquisador com a leitura feita pelo colorímetro atribuindo valores rígidos na conversão dos limites, maior foi a tendência do pesquisador em superestimar o valor do matiz no ato da determinação. Por outro lado, quando considerarmos as leituras convertidas em limites médios, quanto menor a diferença entre os pesquisadores e esta leitura, pode-se considerar que o pesquisador apresentou menor tendência em superestimar os valores de matiz. Neste caso, o pesquisador determina o matiz atribuindo-lhe o valor do padrão mais próximo encontrado na carta de Munsell.

Observa-se clara tendência dos pesquisadores superestimarem as determinações de cor (Tabela 5). Para toda comparação entre as determinações feitas por pesquisadores com determinações feitas pelo colorímetro, adotando o limite médio, houve tendência de os pesquisadores superestimarem este valor. Entre as comparações, um típico exemplo desta constatação é a comparação de P2 com as leituras de cor determinadas através do colorímetro. Tanto para a determinação do matiz úmido como seco, esse pesquisador apresenta tendências em superestimar os limites rígidos e médios, confirmando a constatação de 
Cooper (1990). De acordo com os limites de variação de matiz estabelecidos em Embrapa (1999) para classificação de solos, essa superestimativa pode resultar em erros na classificação.

Diferentes tendências médias entre as determinações do matiz evidenciam grandes possibilidades de ocorrerem erros na classificação utilizando a cor determinada pela comparação com padrões estabelecidos na carta de Munsell, estando envolvido nesse processo, a capacidade do olho humano em caracterizar a cor.

Sendo a cor um importante parâmetro utilizado para distinguir solos, faz-se necessário que metodologias mais precisas na avaliação deste atributo sejam buscadas uma vez considerada a subjetividade atribuída à interpretação do olho humano. Portanto, devem ser buscadas metodologias que utilizem equipamentos precisos e exatos em determinar a cor. Podem ser tomadas como exemplo, as metodologias empregadas em análises de rotina nos laboratórios que utilizam equipamentos para determinar atributos do solos pelas análises químicas e granulométricas. Da mesma forma que os demais atributos dos solos, a cor possui sua importância no estudo dos mesmos, sendo necessário que este parâmetro seja determinado com maior exatidão. $\mathrm{O}$ fato da determinação da cor ser realizada em laboratório vai de encontro às análises de solo tradicionais, que também o são concordando com Kelly \& Judd (1976).

\subsection{CONCLUSÕES}

Foi possível comparar estatisticamente, que os pesquisadores deste trabalho possuem treinamento em avaliar o matiz das amostras. 
A separação das determinações de cor em grupos pela análise "Cluster" demonstrou que existem afinidades e disparidades entre as determinações feitas por pesquisadores e pelo colorímetro.

Houve concordância entre todas as determinações de cor, para uma mesma amostra, somente em 8,75 \% para o matiz das amostras úmidas e $17,5 \%$ para o matiz das amostras secas.

A maior divergência consistiu em duas avaliações diferentes em 2.5 pontos na escala Munsell na da cor de uma mesma amostra entre todas as determinações de matiz.

Em média, os pesquisadores tendem a superestimar os valores de matiz das determinações em Munsell.

Foram detectadas divergências que podem resultar em erros na classificação de solos, sugerindo que medidas com o colorímetro devem substituir as leituras de cor feitas com a carta de Munsell visando a obtenção de determinações mais exatas da cor do solo. 


\section{QUANTIFICAÇÃO DO TEOR DE HEMATITA A PARTIR DA COR DO SOLO}

\section{RESUMO}

A cor do solo é uma propriedade que deriva das características do solo como os óxidos de ferro, daí a importância da quantificação deste atributo. O objetivo deste trabalho foi o de quantificar os teores de hematita por sensoriamento remoto, baseado na cor do solo. A cor de 15 amostras de solos pertencentes a diferentes regiões do Estado de São Paulo foi determinada utilizando um colorímetro e a partir de dados de reflectância obtidos por radiômetro em laboratório. Os dados obtidos por sensoriamento remoto foram base para determinação da cor no sistema $\mathrm{L}^{*} \mathrm{a}^{*} \mathrm{~b}^{*}$ e Munsell. Para cada amostra foram determinados os teores de hematita e calculados os índices de avermelhamento (IAV) a partir das cores obtidas. Os IAVs apresentaram alta correlação com os teores de hematita das amostras, sendo maior para correlações com índices determinados a partir de cores no sistema $\mathrm{L}^{*} \mathrm{a}^{*} \mathrm{~b}^{*}$ do que os no sistema Munsell. Modelos exponenciais, baseados em dados obtidos por sensores, mostraram-se mais adequados na predição dos teores de hematita. 


\section{Summary: ESTIMATIVE OF HEMATITE CONTENTS BY SOIL COLOR}

The color is a property of the soil that derives from its characteristic, as iron oxides, showing the importance of the color on soil attributes estimative. Color of 15 soil samples from different sites in São Paulo State was determined using a colormeter and reflectance data obtained in a radiometer. Colors were determined by $L^{*} a * b *$ and Munsell systems. For each sample, hematite rates were obtained and redness indexes (RI) calculated from color values. The RI showed a high correlation with hematite contents, being higher for correlations with indexes achieved in $\mathrm{L}^{*} \mathrm{a}^{*} \mathrm{~b}$ * system than those obtained in Munsell system. Exponential models were more effective in predicting the hematite contents.

\subsection{INTRODUÇÃO}

O sensoriamento remoto vem sendo utilizado em varias ciências ligadas ao ambiente, as relacionadas ao solo e à planta. Em relação aos solos, trabalhos foram realizados com o intuito de avalia-los por sensoriamento (Madeira Netto et al., 1997; Galvão \& Vitorelo, 1998; Demattê \& Garcia, 1999). Os resultados obtidos por estes autores indicam que atributos do solo podem ser avaliados pela reflectância espectral. Neste aspecto, a cor dos solos mostra-se como uma propriedade diretamente relacionada às características do solo melhor fundamentada pelo sensoriamento remoto, como os óxidos de ferro (Formaggio et al., 1996). Este atributo apresenta alta influência na reflectância que por sua vez se relaciona à cor. Assim, o avermelhamento provocado pela presença da hematita em solos tem levado diversos pesquisadores a proporem índices de avermelhamento que permitam a estimativa do conteúdo desse mineral nos solos. Estes índices são baseados em coordenadas de sistemas de notação de cores, como o Sistema de Munsell e os espaços de cores propostos pela CIE 
(Commission Internationale de l'Eclairage), como o Yxy, estabelecido em 1931, e o L*a*b*, estabelecido em 1976.

O sistema $\mathrm{L}^{*} \mathrm{a} * \mathrm{~b}^{*}$ é uma ferramenta utilizada por mais de $90 \%$ dos usuários de diversas áreas da ciência (Sánchez-Marañon et al., 1995), embora tenha pouca expressão nos trabalhos com solos. Já o sistema Munsell é o mais conhecido entre os pedólogos, estando presente nas cadernetas de campo de avaliação da cor do solo.

Os sistemas propostos pela CIE são baseados na teoria dos três componentes da visão colorida, pela qual o olho possui receptores para as três cores primárias (vermelho, verde, azul) e todas as outras cores são vistas como uma mistura dessas cores. A notação de cores nesses sistemas tem por base os valores de triestímulus que correspondem ao produto da distribuição espectral de potência da fonte de luminante pela reflectância espectral do objeto e pela resposta do olho humano às três cores primárias.

O sistema Munsell é definido em termos dos valores de matiz, valor (brilho) e croma (saturação). A determinação das cores nesse sistema normalmente é feita por comparação visual com uma série de padrões contidos na carta de Munsell.

O método de determinação da cor do solo, utilizando os valores de triestímulos calculados a partir de dados de reflectância das amostras de solo, proposto por Barrón \& Torrent (1986) utiliza amostras secas, ao contrário do que se efetua na determinação em campo, podendo ainda ser efetuado com pequenas quantidades de material e de maneira relativamente simples. Os valores obtidos por esta técnica são considerados mais precisos, uma vez que se evitam interpolações imprecisas, falta de reprodutibilidade e erros subjetivos, passíveis de ocorrer na determinação visual.

Rezende (1980), já apontava a técnica espectrofotométrica como promissora para estimar a relação hematita:goethita em amostras de solo, uma vez 
que observou comportamento diferenciado dos espectros obtidos em função da referida relação para solos brasileiros. Uma feição característica da curva espectral, em torno de 440 a $460 \mathrm{~nm}$, foi identificada e relacionada com o aumento de goethita na amostra, embora o autor tenha encontrado dificuldades em mensurá-la.

Apesar da cor dos pigmentos já ser conhecida, ocorrem fatores que podem afetar sua expressão, e variações são observadas, com implicações diretas na cor do solo. Torrent \& Schwertmann (1987) observaram, para misturas de hematitas sintéticas e caulinitas, que a cor dependia do tamanho da partícula do óxido de ferro e que o aumento deste tamanho resultava em cores mais púrpuras, o que denota diminuição da capacidade de pigmentação da hematita. Essa relação, entretanto, não foi observada em amostras naturais de sedimentos vermelhos (red beds).

Apesar de alguns trabalhos relacionarem teores de hematita com dados de sensoriamento remoto, a determinação continua sendo em análises de laboratório por métodos convencionais. Entretanto, tais métodos mostram-se complexos e não disponíveis em análises rotineiras, além do alto custo e tempo para determinação. Portanto faz-se necessário o desenvolvimento de técnicas mais simples menos onerosas e mais e rápidas. Neste aspecto, o sensoriamento remoto, cujo potencial no estudo do solo é comprovado, poderia auxiliar.

Portanto, este trabalho visa verificar a possibilidade de quantificar os teores de hematita por índices de avermelhamento obtidos a partir da determinação da cor do solo por três diferentes métodos: comparação visual (carta de Munsell), colorímetro e dados de reflectância de amostras de solo. 
Tabela 6. Classificação, localização, profundidade de amostragem e material de origem dos solos estudados.

\begin{tabular}{|c|c|c|c|c|c|}
\hline Num. & Classificação brasileira & Soil Taxonomy & Local de Coleta & Prof. (cm) & Material de origem \\
\hline 1 & LATOSSOLO VERMELHO Acriférico (LV) & Rhodic Acrudox & Ribeirão Preto & $100-140$ & Basalto \\
\hline 2 & LATOSSOLO VERMELHO Eutroférrico (LV) & Rhodic Eutrudox & Iracemápolis & $100-110$ & Basalto \\
\hline 3 & LATOSSOLO VERMELHO Distroférrico (LV) & Rhodic Hapludox & Luís Antônio & $80-100$ & Basalto \\
\hline 4 & LATOSSOLO VERMELHO Acriférico (LV) & Rhodic Acrudox & Luís Antônio & $150-170$ & Basalto \\
\hline 5 & LATOSSOLO AMARELO Ácido (LA) & Xanthic Acrustox & Guaíra & $100-130$ & Basalto \\
\hline 6 & LATOSSOLO VERMELHO Distrófico (LV) & Typic Hapludox & Piracicaba & $100-110$ & Basalto \\
\hline 7 & LATOSSOLO VERMELHO-AMARELO Distrófico (LVA) & Typic Hapludox & Piracicaba & $100-110$ & Arenito \\
\hline 8 & LATOSSOLO VERMELHO-AMARELO Distrófico (LVA) & Typic Hapludox & São Carlos & $80-100$ & Arenito \\
\hline 9 & NITOSSOLO VERMELHO Eutroférrico (NV) & Typic Hapludalf & Piracicaba & $30-40$ & Basalto \\
\hline 10 & ARGISSOLO VERMELHO-AMARELO Distrófico (PVA) & Typic Hapludult & Pindorama & $100-120$ & Arenito \\
\hline 11 & ARGISSOLO VERMELHO-AMARELO Distrófico (PVA) & Typic Hapludult & Vera Cruz & $100-120$ & Arenito \\
\hline 12 & ARGISSOLO VERMELHO Distrófico (PV) & Typic Hapludult & Rio Claro & $70-80$ & Folhelho \\
\hline 13 & ARGISSOLO VERMELHO Distrófico (PV) & Typic Hapludult & Piracicaba & $100-110$ & Basalto \\
\hline 14 & ARGISSOLO VERMELHO-AMARELO Eutrófico (PVA) & Typic Hapludult & São Pedro & $20-35$ & Folhelho \\
\hline 15 & NEOSSOLO QUARTZARÊNICO Órtico (RQ) & Typic Quatzipsamment & São Pedro & $80-100$ & Arenito \\
\hline
\end{tabular}




\subsection{MATERIAL E MÉTODOS}

\subsubsection{Solos e análises mineralógicas}

Foram utilizadas amostras de terra num total de 15 e as respectivas análises dos teores de hematita ${ }^{(1)}$ provindas de diferentes regiões (Tabela 6).

O método para estimativa dos teores de hematita foi de acordo com (Resende, 1976; Netto, 1996). Tal método se fundamenta na divisão do teor de $\mathrm{Fe}_{2} \mathrm{O}_{3}$ presente nos óxidos de ferro cristalinos da fração argila em teores associados aos minerais hematita e goethita, possibilitando assim a semiquantificação dos mesmos.

\subsubsection{Obtenção da curva de reflectância espectral}

A aquisição dos dados espectrais das amostras de terra secas e peneiradas em tamis de $2 \mathrm{~mm}$, foi realizada com o sensor Fieldspec na faixa de 380 e $780 \mathrm{~nm}$ e resolução espectral de $1 \mathrm{~nm}$. O sensor realiza, em média, 10 repetições para cada amostra. Como fonte de iluminação foi utilizada uma lâmpada halógena de $650 \mathrm{~W}$, com feixe não colimado para o plano visado. Como padrão de referência, foi utilizada uma placa branca, com $100 \%$ de reflectância. A razão entre o fluxo radiante espectral refletido pela superfície de uma amostra de solo e o fluxo radiante espectral refletido por um padrão de referência iluminados e visados sob as mesmas condições geométricas, gerou o fator de reflectância.

\subsubsection{Determinação das cores}

As cores das amostras de terra foram determinadas em amostras secas, por dois diferentes métodos: por colorímetro e a partir dos dados de reflectância espectral das amostras.

(1) Análise cedida por Marcelo E. Alves (Doutorando do Curso de Solos e Nutrição de Plantas, ESALQ/USP) 
Na determinação por colorímetro utilizou-se o aparelho Minolta, modelo CR 300, com capacidade de leitura em diferentes sistemas de cores, dos quais foram utilizados o sistema Munsell e o sistema $\mathrm{L}^{*} \mathrm{a}^{*} \mathrm{~b}^{*}$ definido pela CIE em 1976. No sistema $\mathrm{L}^{*} \mathrm{a}^{*} \mathrm{~b}^{*}$ as cores são definidas pelo brilho $\left(\mathrm{L}^{*}\right)$ e pelas coordenadas de cromaticidade $\left(\mathrm{a}^{*}\right.$ e $\mathrm{b}^{*}$ ), onde valores positivos de $\mathrm{a}^{*}$ estão relacionados à cor vermelha; valores negativos de $\mathrm{a}^{*}$ à cor verde, valores positivos de $\mathrm{b}^{*}$ à cor amarela e valores negativos de $\mathrm{b}^{*}$ à cor azul. Como $\mathrm{a}$ notação das cores no sistema $\mathrm{L} * \mathrm{a} * \mathrm{~b} *$ varia com o ângulo de visão do observador e a fonte de iluminação usada, o colorímetro foi programado para executar leituras considerando o observador padrão CIE de 1931 com campo de visão de $2^{\circ}$ e o iluminante $\mathrm{C}$, também padronizado pela CIE.

$\mathrm{Na}$ determinação das cores pelos dados de reflectância espectral, foram determinados inicialmente os valores de triestímulos XYZ definidos pela CIE em 1931, para o observador padrão CIE 1931 com $2^{\circ}$ de campo de visão. As equações utilizadas são apresentadas a seguir:

$$
\begin{aligned}
& X=K \int_{380}^{780} S(\lambda) R(\lambda) \bar{x}(\lambda) d \lambda \\
& Y=K \int_{380}^{780} S(\lambda) R(\lambda) \bar{y}(\lambda) d \lambda \\
& Z=K \int_{380}^{780} S(\lambda) R(\lambda) \bar{z}(\lambda) d \lambda \\
& K=\frac{100}{\int_{380}^{780} S(\lambda) \bar{y}(\lambda) d \lambda}
\end{aligned}
$$

sendo:

$\lambda$ é o comprimento de onda da radiação em $\mathrm{nm}$;

$S(\lambda)$ é a distribuição espectral de potência relativa do iluminante. Utilizou-se o iluminante D65, padronizado pela CIE; 
$R(\lambda)$ é a reflectância espectral da amostra;

$\bar{x}(\lambda), \bar{y}(\lambda), \bar{z}(\lambda)$ são as funções que definem, respectivamente, as respostas do olho humano às cores vermelho, verde e azul para um observador padrão com campo de visão de $2^{\circ}$ em função do comprimento de onda $(\lambda)$ da radiação. Estas funções também são padronizadas pela CIE.

Todos os dados foram disponibilizados em intervalos de comprimento de onda de $1 \mathrm{~nm}$. O cálculo das integrais foi aproximado através da regra dos trapézios.

Os valores de triestímulos $\mathrm{XYZ}$ foram transformados nas coordenadas do sistema $\mathrm{L}^{*} \mathrm{a}^{*} \mathrm{~b}^{*}$, através das Equações 5 a 7 :

$$
\begin{aligned}
& \mathrm{L}^{*}=116\left(\frac{\mathrm{Y}}{\mathrm{Y}_{\mathrm{n}}}\right)^{1 / 3}-16 \\
& \mathrm{a}^{*}=500\left[\left(\frac{\mathrm{X}}{\mathrm{X}_{\mathrm{n}}}\right)^{1 / 3}-\left(\frac{\mathrm{Y}}{\mathrm{Y}_{\mathrm{n}}}\right)^{1 / 3}\right] \\
& \mathrm{b}^{*}=200\left[\left(\frac{\mathrm{Y}}{\mathrm{Y}_{\mathrm{n}}}\right)^{1 / 3}-\left(\frac{\mathrm{Z}}{\mathrm{Z}_{\mathrm{n}}}\right)^{1 / 3}\right]
\end{aligned}
$$

sendo;

$X_{n}, Y_{n}, Z_{n}$ são os valores dos triestímulos para o iluminante D65, considerando o observador padrão CIE 1931 com ângulo de visão de $2^{\circ}$, a saber: $\mathrm{Xn}=95,045$, $\mathrm{Yn}=100,00$ e $\mathrm{Zn}=108,892$.

Para valores de $\mathrm{X} / \mathrm{X}_{\mathrm{n}}, \mathrm{Y} / \mathrm{Y}_{\mathrm{n}}, \mathrm{Z} / \mathrm{Z}_{\mathrm{n}}$ menores que 0,008856 , as equações acima mudam através das seguintes substituições de termos:

$$
\begin{aligned}
& \left(\frac{\mathrm{X}}{\mathrm{X}_{\mathrm{n}}}\right)^{1 / 3} \text { por } 7,787\left(\frac{\mathrm{X}}{\mathrm{X}_{\mathrm{n}}}\right)+\frac{16}{116} \\
& \left(\frac{\mathrm{Y}}{\mathrm{Y}_{\mathrm{n}}}\right)^{1 / 3} \operatorname{por} 7,787\left(\frac{\mathrm{Y}}{\mathrm{Y}_{\mathrm{n}}}\right)+\frac{16}{116}
\end{aligned}
$$




$$
\left(\frac{\mathrm{Z}}{\mathrm{Z}_{\mathrm{n}}}\right)^{1 / 3} \text { por } 7,787\left(\frac{\mathrm{Z}}{\mathrm{Z}_{\mathrm{n}}}\right)+\frac{16}{116}
$$

\subsection{4 Índices de avermelhamento}

Os índices de avermelhamento foram calculados a partir das equações propostas por Barron \& Torrent (1986). A equação 8 foi proposta para cores expressas no sistema Munsell; a equação 9 para cores expressas no sistema $\mathrm{L} * \mathrm{a} * \mathrm{~b} *$. As letras $\mathrm{H}, \mathrm{V}$ e $\mathrm{C}$ significam, respectivamente os valores de matiz, valor (ou brilho) e croma (ou saturação) das cores do sistema Munsell. Os valores de matiz no sistema de Munsell são formados por uma combinação de números e letras. Quando o valor numérico do matiz é seguido pelas letras YR deve-se utilizar apenas os valores numéricos na fórmula do índice de avermelhamento, porém para o matiz 10YR deve-se utilizar H igual a 10 e para o matiz $10 \mathrm{R}, \mathrm{H}$ igual a zero.

$$
\begin{aligned}
& \operatorname{IAV}_{\text {Munsell }}=\frac{(10-\mathrm{H})^{3} \cdot \mathrm{C} \cdot 10^{3}}{\mathrm{~V}^{6}} \\
& \mathrm{IAV}_{\mathrm{Lab}}=\frac{\mathrm{a} *\left(\mathrm{a} *^{2}+\mathrm{b}^{2}\right)^{\frac{1}{2}} \cdot 10^{10}}{\mathrm{~b} * \mathrm{~L}^{* 6}}
\end{aligned}
$$

\subsection{RESULTADOS E DISCUSSÃO}

Ao proporem os índices de avermelhamento para amostras de solo (Equações 8 e 9), Barron \& Torrent (1986) testaram vários expoentes para os termos que compõem os índices visando a obtenção de uma correlação máxima 
entre as variáveis índice de avermelhamento e teor de hematita. Utilizando modelos de regressão linear, estes pesquisadores obtiveram boas correlações $\left(\mathrm{R}^{2}\right.$ superiores a 0,995), quando os teores de hematita eram inferiores a $150 \mathrm{~g} \mathrm{~kg}^{-1} \mathrm{em}$ amostras de solo desferrificadas com adição de conteúdos conhecidos de hematita sintética. Quando as equações de regressão obtidas foram utilizadas em amostras de solos com teores de hematita determinados por técnicas de difração de raios-X, os coeficientes de determinação foram menores: 0,67 para cores no sistema Munsell e 0,87 para cores no sistema L*a*b*.

Neste trabalho, os teores de hematita das amostras variaram de 0 a $223,5 \mathrm{~g}$ $\mathrm{kg}^{-1}$ (Tabela 7), compreendendo uma faixa de variação mais ampla do que a das

Tabela 7. Teores de hematita e os índices de avermelhamento obtidos para as amostras de solo

\begin{tabular}{rrrrrr}
\hline Amostra & Solo & $\begin{array}{r}\text { Teor de } \\
\text { Hematita }\left(\mathrm{g} \mathrm{kg}^{-1}\right)\end{array}$ & $\begin{array}{r}\mathrm{IAV}^{2} \text { (Munsell) } \\
\text { (colorímetro) }\end{array}$ & $\begin{array}{r}\mathrm{IAV}^{2}\left(\mathrm{~L}^{*} \mathrm{a}^{*} \mathrm{~b}^{*}\right) \\
\text { (colorímetro) }\end{array}$ & $\begin{array}{r}\mathrm{IAV}^{2}\left(\mathrm{~L}^{*} \mathrm{a}^{*} \mathrm{~b}^{*}\right) \\
\text { (reflectância) }\end{array}$ \\
\hline 1 & LV1 & 223,5 & 346,83 & 139,29 & 217,89 \\
2 & LV2 & 204,8 & 275,32 & 134,11 & 326,15 \\
3 & LV3 & 210,7 & 307,55 & 127,12 & 252,54 \\
4 & LV4 & 223,5 & 264,46 & 113,82 & 296,01 \\
5 & LA1 & 0,0 & 0,54 & 4,54 & 6,41 \\
6 & LV5 & 23,0 & 54,01 & 12,81 & 25,11 \\
7 & LVA1 & 20,6 & 25,48 & 12,36 & 16,56 \\
8 & LVA2 & 1,9 & 8,77 & 7,89 & 11,56 \\
9 & NV1 & 127,6 & 105,74 & 30,66 & 61,66 \\
10 & PVA1 & 2,7 & 7,76 & 6,14 & 9,84 \\
11 & PVA2 & 14,0 & 13,36 & 6,18 & 9,00 \\
12 & PV1 & 23,4 & 7,36 & 8,37 & 17,40 \\
13 & PV2 & 25,5 & 25,14 & 7,43 & 9,48 \\
14 & PVA3 & 10,6 & 3,74 & 7,09 & 10,67 \\
15 & RQ1 & 5,6 & 6,29 & 8,55 & 9,06 \\
\hline
\end{tabular}

${ }^{1}$ Sigla dos solos de acordo com Embrapa (1999); ${ }^{2}$ Índice de avermelhamento.

amostras de Barron \& Torrent (1986). A disposição dos dados em diagrama de dispersão mostrou tendências de relações exponenciais entre os índices de 
avermelhamento e os teores de hematita. Optou-se, portanto, pela aplicação do modelo estatístico de regressão $\mathrm{Y}_{\mathrm{i}}=\beta_{0} \mathrm{e}^{\beta_{1} \mathrm{X}_{\mathrm{i}}} \varepsilon_{\mathrm{i}}$. Este modelo foi linearizado por transformações logarítmicas resultando no modelo: $Y_{i}{ }^{\prime}=\beta_{0}{ }^{\prime}+\beta_{1} X_{i}+\varepsilon_{i}{ }^{\prime}$, sendo $Y_{\mathrm{i}}^{\prime}=\ln \mathrm{Y}_{\mathrm{i}}, \quad \beta_{0}^{\prime}=\ln \beta_{0}$ e $\varepsilon_{\mathrm{i}}^{\prime}=\ln \varepsilon_{\mathrm{i}}$.

As equações das retas estimadas pelo método de mínimos quadrados para o modelo linearizado e seus respectivos coeficientes de determinação $\left(\mathrm{R}^{2}\right)$ são apresentados nas Figuras 2 e 3 . Os intervalos de $95 \%$ de confiança para $\mathrm{E}\left(\mathrm{Y} \mid \mathrm{X}_{0}\right)$ e de predição de $95 \%$ também são apresentados nas mesmas figuras. Testes de hipóteses baseados nas estatísticas $\mathrm{F}$ e $\mathrm{t}$ rejeitam a hipótese $\mathrm{H}_{0}$ : $\beta_{1}=0$ ao nível de $5 \%$ de significância em todos os casos analisados indicando a existência de uma relação linear entre os logaritmos dos índices de avermelhamento e os teores de hematita.

Os valores de $\mathrm{R}^{2}$ obtidos mostram alta correlação entre as variáveis teor de de hematita e o logaritmo natural do IAV calculado a partir das cores no sistema $\mathrm{L} * \mathrm{a} * \mathrm{~b} *$ fornecidas pelo colorímetro ou obtidas a partir de dados de reflectância (Figuras 2 e 3). Quando utilizado o índice de avermelhamento para as cores no sistema Munsell, o coeficiente de determinação é menor e a estimativa dos índices de avermelhamento para um certo teor de hematita é menos precisa. O intervalo de confiança fornece informações sobre a precisão das estimativas, no sentido de quanto menor a amplitude do intervalo, maior a precisão. 
$\mathbf{a}$

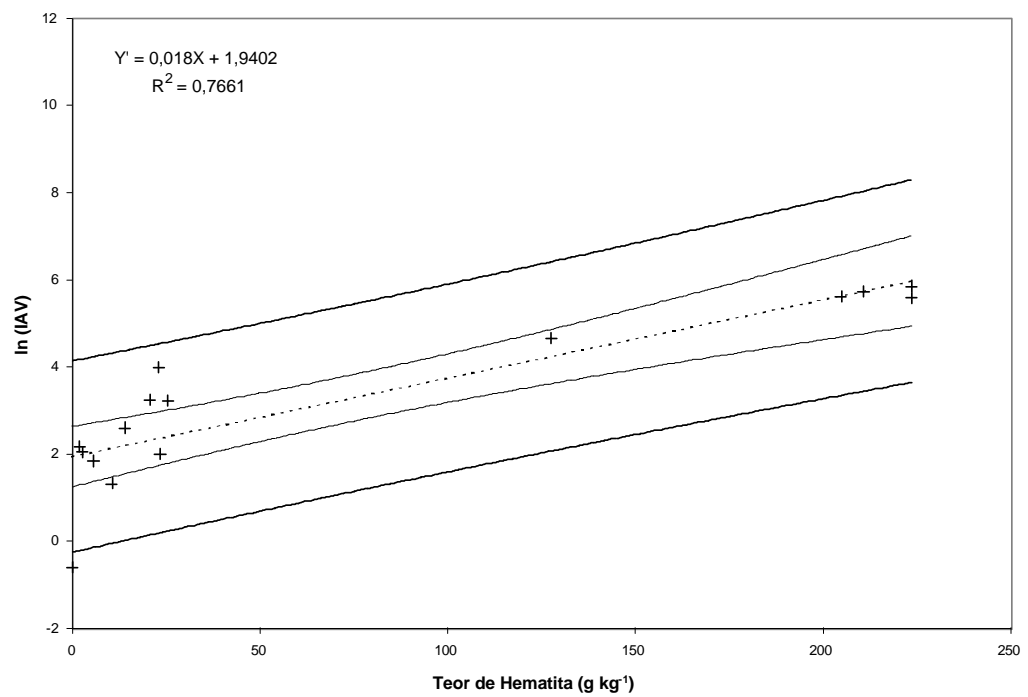

b

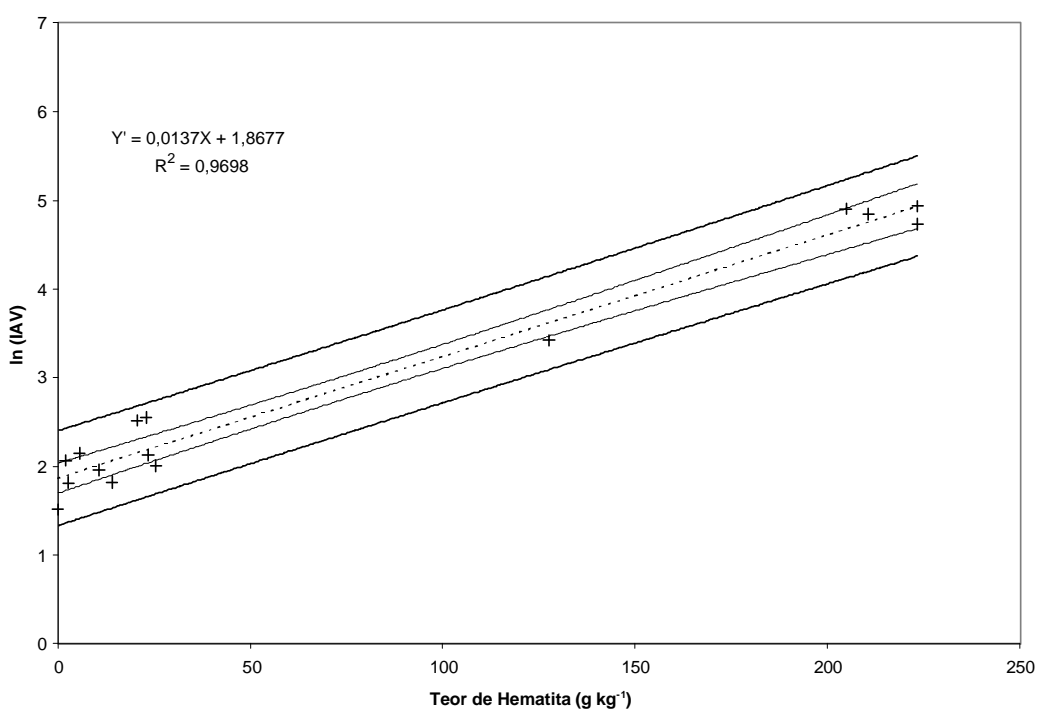

Figura 2 - (a) Gráfico ln (IAV) vs. Teor de Hematita para IAV calculados a partir das leituras de cor de amostras de solo fornecidas pelo colorímetro no Sistema Munsell; (b) Gráfico ln (IAV) vs. Teor de Hematita para IAV calculados a partir das leituras de cor de amostras de solo fornecidas pelo colorímetro no sistema $\mathrm{L}^{*} \mathrm{a} \mathrm{b}^{*}$. As linhas tracejadas representam as retas ajustadas para o modelo exponencial linearizado; as duas linhas cheias externas representam os limites do intervalo de predição de $95 \%$ para $\mathrm{Y}^{\prime}$ relativo a uma nova observação com teor de hematita igual a $\mathrm{X}_{0}$; as duas linhas cheias internas representam os limites do intervalo de $95 \%$ de confiança para $\mathrm{E}\left(\mathrm{Y}^{\prime} \mid \mathrm{X}_{0}\right)$. Os sinais "+ " representam os valores observados utilizados no 


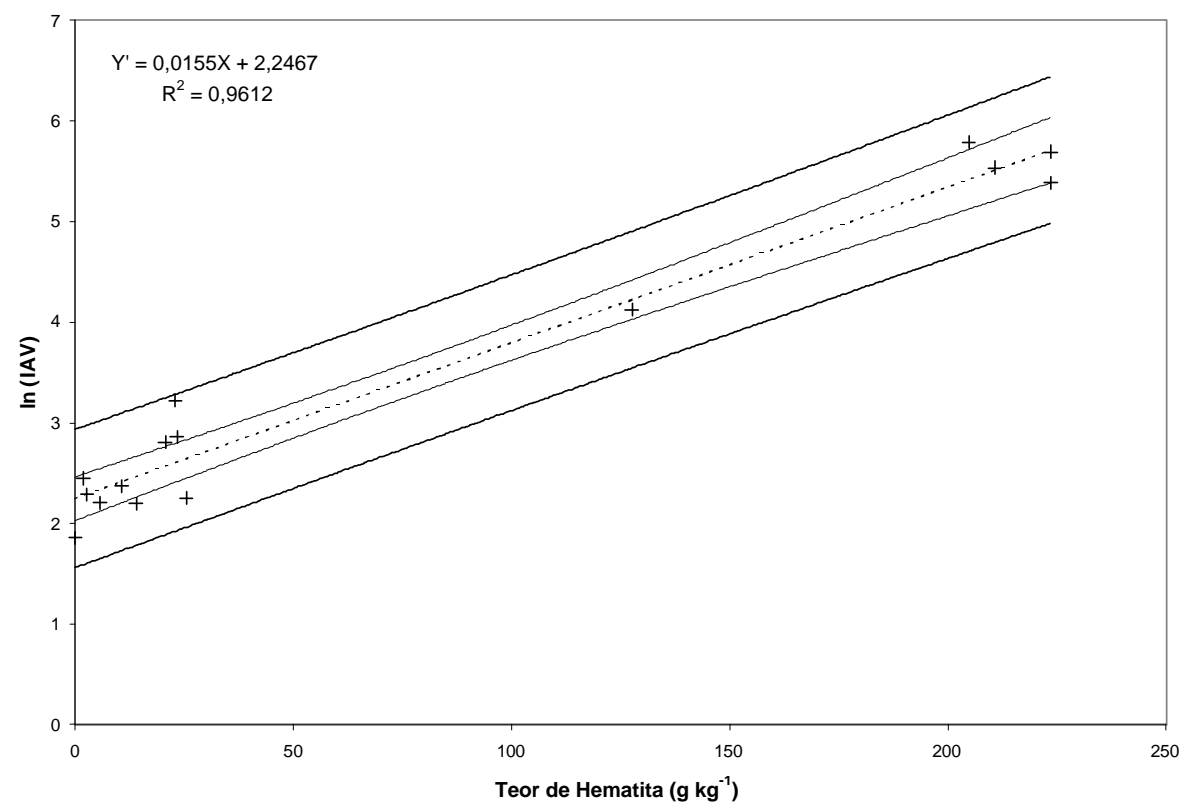

Figura 3 - Gráfico ln (IAV) vs. Teor de Hematita para IAV calculados a partir das cores no sistema $\mathrm{L}^{*} \mathrm{a} * \mathrm{~b} *$ obtidas a partir de dados de reflectância das amostras de solos. A linha tracejada representa a reta ajustada para o modelo exponencial linearizado; as duas linhas cheias externas representam os limites do intervalo de predição para $Y^{\prime}$ relativo a uma nova observação com teor de hematita igual a $\mathrm{X}_{0}$; as duas linhas cheias internas representam o limite do intervalo de confiança para $\mathrm{E}\left(\mathrm{Y}^{\prime} \mid \mathrm{X}_{0}\right)$. Os sinais "+ " representam os valores observados utilizados no ajuste.

As equações de regressão obtidas, especialmente para as cores expressas no sistema $\mathrm{L}^{*} \mathrm{a}^{*} \mathrm{~b}$, demonstram um bom potencial na estimação dos conteúdos de hematita em solos. A obtenção de parâmetros colorimétricos a partir de dados de reflectância na região do visível, como os índices de avermelhamento, exibe grande potencial de utilização na área de sensoriamento remoto. Pesquisas que buscam estabelecer relações quantitativas entre componentes mineralógicos e dados de reflectância dos solos, ganham cada vez mais importância, a medida que os resultados demonstram ser possível prever os atributos dos solos a partir de dados de reflectância, concordando com Madeira Netto et al. (1997), Demattê \& Garcia (1999) e Nanni \& Demattê (2001)

A leitura das cores através do colorímetro é um método mais rápido e fácil de determinação de cores e mostrou-se tão eficiente na avaliação do índice de 
avermelhamento e sua relação com os teores de hematita de solos quanto o cálculo das cores a partir dos dados de reflectância.

Deve-se ressaltar que as coordenadas $\mathrm{L}^{*} \mathrm{a} * \mathrm{~b} *$ fornecidas pelo colorímetro são para amostras iluminadas por uma fonte com distribuição espectral de potência igual ao iluminante padrão C; já no cálculo das coordenadas por dados de reflectância utilizou-se o iluminante padrão D65. Portanto, as diferenças nas coordenadas de cores $\mathrm{L} * \mathrm{a} * \mathrm{~b} *$ para uma mesma amostra, devem-se não somente aos diferentes métodos utilizados, mas também aos diferentes iluminantes utilizados em cada método.

Madeira Netto et al. (1997) obtiveram correlações de $R^{2}$ igual a 0,95 entre reflectância e teores de hematita de solos, enquanto o presente trabalho obteve $\mathrm{R}^{2}$ igual 0,96. Apesar dos métodos serem diferentes, a base para determinação dos modelos, ou seja a reflectância, ratificando seu potencial na quantificação de atributos do solo.

A aplicação das equações de regressão obtidas são válidas apenas quando as cores são determinadas pelo mesmo método e sob o mesmo iluminante utilizados na estimação de cada equação.

O comportamento dos modelos exponenciais são semelhantes ao comportamento dos modelos lineares para baixos valores de hematita, o que não invalida as equações de regressão obtidas por Barron \& Torrent (1986).

Mesmo com diferentes iluminantes, a hipótese de igualdade dos coeficientes angulares das retas de regressão para índices de avermelhamento obtidas a partir das coordenadas $L * a * b *$ não é rejeitada pela estatística $\mathrm{F}$ ao nível de $5 \%$ de probabilidade, embora o mesmo teste rejeite a hipótese de igualdade dos coeficientes lineares. Há, portanto, evidências que as retas ajustadas são paralelas, implicando numa mesma taxa de variação do IAV em relação ao teor de hematita em ambos os casos. 
A utilização dos modelos exponenciais linearizados torna possível o cálculo dos parâmetros $\beta_{0}^{\prime}$ e $\beta_{1}$ das equações de regressão, além de tornar o modelo mais simples para análises e predições; entretanto deve-se ressaltar que os dados correspondentes à variável dependente (IAV) devem sofrer uma transformação logarítmica. Caso queira-se trabalhar com os modelos na forma exponencial, basta, a partir do parâmetro $\beta_{0}{ }^{\prime}$ do modelo linearizado, obter o parâmetro $\beta_{0}$ através da equação $\beta_{0}=\mathrm{e}^{\beta_{0}^{\prime}}$. Os gráficos e equações de regressão na forma exponencial são apresentados nas Figuras 4 e 5.

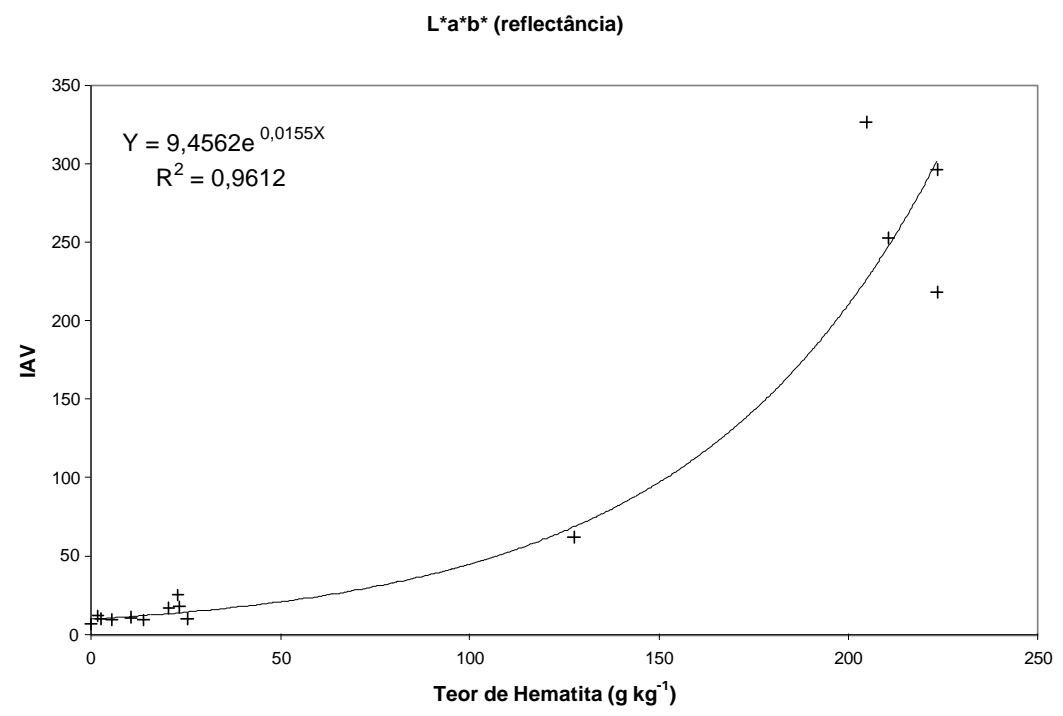

Figura 4. Gráfico IAV vs. Teor de Hematita para cores no sistema L*a*b* determinadas a partir de dados de reflectância obtidos com radiômetro. 

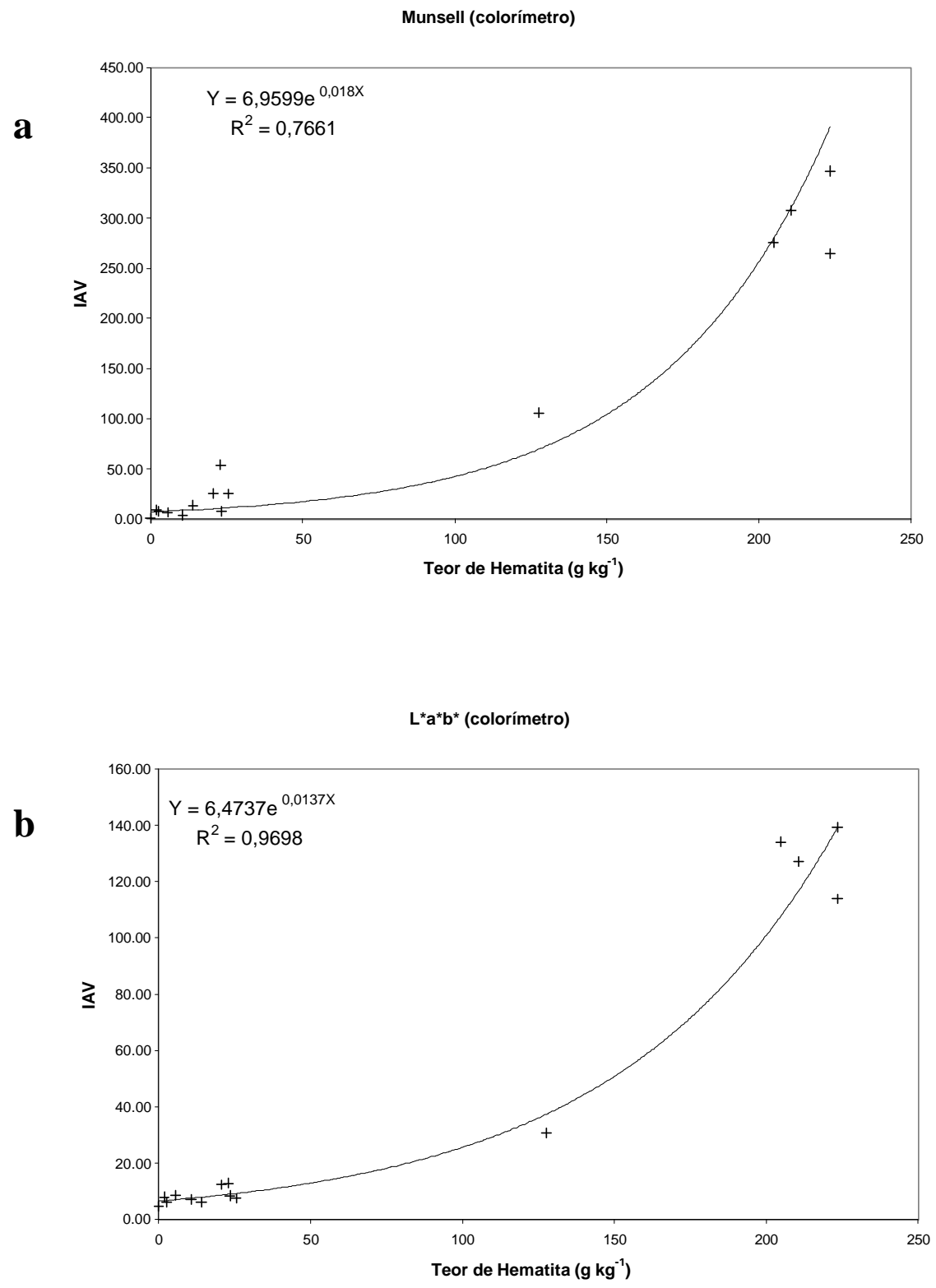

Figura 5 - (a) Gráficos IAV vs Teor de Hematita para cores determiandas no sistema Munsell com o colorímetro.

(b) Gráfico IAV vs. teor de hematita para cores determinadas no sistema L*a*b* com o colorímetro 


\subsection{CONCLUSÕES}

É possível determinar os teores de hematita em solos a partir da obtenção de índices de avermelhamento através de leituras de cor no sistema $\mathrm{L}^{*} \mathrm{a} * \mathrm{~b}^{*}$ ou Munsell determinadas com dados de sensoriamento remoto.

Os modelos exponenciais de regressão entre o IAV e os teores de hematita são mais adequados para teores variando de 0 a $220 \mathrm{~g} \mathrm{~kg}^{-1}$.

As melhores correlações e as menores amplitudes de intervalos de confiança entre IAV e teores de hematita, são conseguidas pela determinação de cores no sistema $\mathrm{L}^{*} \mathrm{a}^{*} \mathrm{~b}^{*}$ por colorímetro ou por dados de reflectância de amostras de solos. 


\section{CONCLUSÕES GERAIS}

As divergências entre experientes pesquisadores na determinação do matiz das amostras de solos confirma que o método convencional utilizado para determinação da cor, apresenta determinada subjetividade que é atribuída à características particulares de cada observador. Desta forma, esse método não pode ser utilizado para determinações da cor do solo com objetivos de se atingir exatidão. Sugere-se que equipamentos que eliminam a subjetividade nas determinações da cor do solo como colorímetros e radiômetros, sejam utilizados como procedimentos de rotina em laboratórios de análise de solos.

O estabelecimento de uma nova metodologia para determinação da cor do solo, utilizando equipamentos como os citados neste trabalho, implica em ganho de exatidão na determinação da cor, permitindo a eliminação de erros e divergências na classificação de solos.

A determinação da cor do solo de forma quantitativa utilizando equipamentos, bem como a determinação da cor no sistema $L^{*} a^{*} b^{*}$, permitiu a obtenção de modelos de correlação que possibilitaram realizar a predição de teores de hematita a partir da cor do solo. 


\section{REFERÊNCIAS BIBLIOGRÁFICAS}

BARRÓN, V. Influencia de los oxidos de hierro en el color de los suelos. Córdoba, 1985. 200p. Thesis (Doutorado) - Universidad de Córdoba.

BARRÓN, V., MELLO, J.W.V., TORRENT, J. Caracterização de óxidos de ferro em solos por espectroscopia de reflectância difusa. Tópicos em Ciência do Solo. Viçosa: SBCS, p.139-159, 1999.

BARRÓN, V., TORRENT, J. Use of the Kubelka-Munk theory to study the influence of iron oxides on soil colour. Journal of Soil Science, v.37, p.499-510, 1986.

BIGHAM, M. F.; CIOLKOSZ, E. J. Soil color. Madison: Soil Science Society of America. 1993. 159p. (Special Publication, 31).

BILLMEYER, F. W.; M. SALTZMAN. Principles of color and tecnology. 2.ed. New York: John Wiley, 1981, 89p.

CAMARGO, A. O.; KLANT, E.; KAUFFMAN, J. H. Classificação de solos usada em levantamentos pedológicos no Brasil. Campinas. Boletim Informativo da Sociedade Brasileira de Ciência do Solo, v. 12. n, 1, p.1113, jan./abr., 1987. 
CHAMBERLIN, G. J.; CHAMBERLIN, D. G. Colour: its measurements, computation and application. Philadelphia: Heyden and Sons, 1980. 1v.

COMMISSION INTERNATIONALE DE L’ECLAIRAGE. Proceedings of the eight session, Cambridge.. Bureau Central de la CIE, 1931.

COOPER, T. H. Development of students' abilities to match soil color to Munsell color chips. Journal of Agronomy Education., v. 19, p. 141-144, 1990.

COSTA, L.M. Surface soil color and reflectance as related to physicochemical and mineralogical soil properties. Columbia, 1979. 154p. Thesis $(\mathrm{PhD})$ - University of Missouri.

DEMATTÊ, J. A. M.; GARCIA, G. J. Alteration of soil properties through a weathering sequence as evaluated by spectral reflectance. Soil Science Society of America Journal, v. 63, n. 2, p. 327-342, 1999.

EMPRESA BRASILEIRA DE PESQUISA AGROPECUÁRIA. Serviço Nacional de Levantamento e Conservação de Solos. Manual de métodos de análise de solo. Rio de Janeiro, 1979. 1v.

EMPRESA BRASILEIRA DE PESQUISA AGROPECUÁRIA. Sistema brasileiro de classificação de solos. Brasília: Embrapa Produção de informação; Rio de Janeiro: Embrapa Solos, 1999. 412 p.

ESCADAFAL, R.; GIRARD, M. C. ; COURAULT, D.. Munsell soil color and soil reflectance in the visible spectral bands of TM/Landsat-5 MSS and TM data. Remote Sensing of Environment, v.27, p.37-46, 1989 
EVANS, R. M. An instructions to color. New York: John Wiley, 1948. 134p.

FAO. Mapa mundial de suelos: leyenda revisada. Rome. 1989. (Informes sobre Recursos Mundiales de Solos, 60).

FERNANDES, R.B.A.; BARRÓN, V.; TORRENT, J. Effect of organic matter on the iron oxides. Identification and quantification from second derivative diffuse reflectance spectra of Brazilian Oxisols. In: WORLD CONGRESS OF SOIL SCIENCE, 16. Montpellier, 1998. v.1. p.441.

FERNANDEZ, R. N.; SCHULZE, D. G.. Calculation of soil color from reflectance spectra. Soil Science Society of America Journal, v.51, p.1277$1282,1987$.

FERNANDEZ, R.N., SCHULZE, D.G. Munsell colors of soils simulated by mixtures of goethite and hematite with kaolinite. Zeitschrift fur Pflanzenernähr Bodenk, v.155, p.473-478, 1992.

FORMAGGIO, A. R.; EPIPHANIO, J. C. N.; VALERIANO, M. M.; OLIVEIRA, J. B. Comportamento espectral (450-2.450 nm) de solos tropicais de São Paulo. Revista Brasileira de Ciência do Solo, Campinas, p. 467-474, 1996.

GALVÃO, L.S., VITORELLO, I. Role of organic matter in obliterating the effects of iron on spectral reflectance and color of Brazilian tropical soils. International Journal of Remote Sensing. v.19, n.10, p.1969$1979,1998$. 
KELLY, K. L.; JUDD, D. B. Color: universal language and dictionary of names. Washington: Natural Bureau of Standart. 1976 (Special Publication, 440).

KOSMAS, C.S.; CURI, N.; BRYANT, R.B. Characterization of iron oxide minerals by second-derivative visible spectroscopy Soil Science Society of America Journal, v.48, p.401-405, 1984

KUBELKA, P.; MUNK, F. Ein beitrag zur otipk der farbanstriche. Zeitschrift fur Technological Physi, 12, p. 593-620, 1931.

MADEIRA NETTO, J. A.; BÉDIDI, A.; CERVELlE, B. Visible spectrometric indices of hematite $(\mathrm{Hm})$ and goethite $(\mathrm{Gt})$ content in lateritic soils: the aplication of a Thematic Mapper (TM) image for soilmapping in Brasilia, Brazil. International Journal of Remote Sensing, v.18, p.2835-2852, 1997.

MELVILLE, M. D.; G. ATKINSON. Soil color; Its measurement and its designation in models of form color space. Soil Science Society of America Journal, v.36, p.495-512, 1985.

MUNSELL SOIL COLOR COMPANY. Munsell soil color charts, Baltimore, 1975. $1 \mathrm{v}$.

NAGANO, T.; NAKASHIMA, S. Study of colors and degrees of weathering of granitic rocks by visible diffuse reflectance spectroscopy. Geochemical Journal, v.23, p.75-83, 1989. 
NANNI, M. R. Dados radiométricos obtidos em laboratório e no nível orbital na caracterização e mapeamento de solos. Piracicaba, 2000, 365p. Tese (Doutorado) - Escola Superior de Agricultura Luiz de Queiroz, USP.

NANNI, M.R., DEMATTÊ, J. A. M.Quantification and discrimination of soils developed from basalt as evaluated by terrestrial, airborne and orbital sensors. Simpósio Brasileiro de Sensoriamento Remoto, 10; Foz do Iguaçu, de 2001.

NETTO, A.R. Influência da mineralogia da fração argila sobre propriedades físico-químicas de solos brasileiros. Viçosa, 1996. 144p. Dissertação (Mestrado) - Universidade Federal de Viçosa.

NORRISH, K., TAYLOR, R.M. The isomorphous replacement of iron by aluminium in soil goethites. Journal of Soil Science, v.12, p.294-306, 1961.

POMERENING, J. A.; KNOX, E. G. Interpolation of Munsell soil color measurements. Soil Science Society of America Journal, v. 26, p.301-302, 1962.

POST, D. F.; BRYANT, R. B.; BATCHILY, A. K.; HUETE.; A.R. Correlations betweem field and laboratory measurements of soil color. Madison: SSSA, 1993. (SSSA Special Publication, 31).

RESENDE, M. Mineralogy, chemistry, morphology and geomorphology of some soils of the Central Plateau of Brazil. West Lafayette, 1976. 237p. Thesis $(\mathrm{PhD})-$ Purdue University . 
REZENDE, S.B. Geomorphology, mineralogy and genesis of four soils on gneiss in Southeastern Brazil. Lafayette, 1980. 143p. Thesis (PhD) Purdue University.

SÁNCHEZ-MARAÑóN, M., DELGADO, G., DELGADO, R., PÉREZ, M.M., MELGOSA, M. Spectroradiometric and visual color measurements of disturbed and undisturbed soil samples. Soil Science, v.160, p.291-303, 1995.

SANTANA, D.P. Soil formation in a toposequence of oxisols from Patos de Minas region, Minas Gerais State, Brazil. Lafayette, 1984. 129p. Thesis $(\mathrm{PhD})$ - Purdue University.

SCHEINOST, A.C., CHAVERNAS, A., BARRÓN, V., TORRENT, J. Use and limitations of second-derivative diffuse reflectance spectroscopy in the visible to near-infrared range to identify and quantify Fe oxides in soils. Clays and Clay Minerals, v.46, p.528-537, 1998.

SCHWERTMANN, U.; TAYLOR, R. M. Iron oxides. In DIXON, J. B.; WEED, S.B. (Ed.). Minerals in soil environments. Madison: SSSA, 1977, p.145180.

STATISTICAL ANALYSIS SYSTEM INSTITUTE. SAS/STAT ${ }^{\mathbf{r}}$ : user's guide; version 6. 4.ed. Cary. 1989. 2v.

SOIL SURVEY STAFF. Soil survey manual. Washington: USDA, 1988. (USDA Handbook, 18). 
TORRENT, J., BARRÓN, V. Laboratory measurement of soil color: theory and practice. Soil color. Madison: SSSA, 1993. p.21-33 (SSSA, Special Publication, 31).

TORRENT, J., SCHWERTMANN, U. Influence of hematite on the color of red beds. Journal of Sedimentary Petrology, v.57, p.682-686, 1987.

WYSZECKI, G.; STILES, W.S. Color science: Concepts and methods, quantitative data and formulae 2 ed., New York, John Wiley,. 1982. 123p. 